\title{
Orion Crew Module Aerodynamic Testing
}

\author{
Kelly J. Murphy ${ }^{*}$, Karen L. Bibb ${ }^{\dagger}$, Gregory J. Brauckmann $\star$, Matthew N. Rhode $\$$, \\ Bruce Owens $^{* *}$, David T. Chan ${ }^{\dagger \dagger}$, Eric L. Walker $+\dagger$ \\ NASA Langley Research Center, Hampton, Virginia, 23681 \\ James H. Bell§§ \\ NASA Ames Research Center, Mountain View, California, 94040 \\ Thomas M. Wilson ${ }^{* * *}$ \\ ESCG/ERC Inc., Houston, Texas, 77058
}

\begin{abstract}
The Apollo-derived Orion Crew Exploration Vehicle (CEV), part of NASA's now-cancelled Constellation Program, has become the reference design for the new Multi-Purpose Crew Vehicle (MPCV). The MPCV will serve as the exploration vehicle for all near-term human space missions. A strategic wind-tunnel test program has been executed at numerous facilities throughout the country to support several phases of aerodynamic database development for the Orion spacecraft. This paper presents a summary of the experimental static aerodynamic data collected to-date for the Orion Crew Module (CM) capsule. The test program described herein involved personnel and resources from NASA Langley Research Center, NASA Ames Research Center, NASA Johnson Space Flight Center, Arnold Engineering and Development Center, Lockheed Martin Space Sciences, and Orbital Sciences. Data has been compiled from eight different wind tunnel tests in the CEV Aerosciences Program. Comparisons are made as appropriate to highlight effects of angle of attack, Mach number, Reynolds number, and model support system effects.
\end{abstract}

\section{Nomenclature}

$\begin{array}{ll}\mathrm{C}_{\mathrm{D}} & =\text { drag-force coefficient } \\ \mathrm{C}_{\mathrm{L}} & =\text { lift-force coefficient } \\ \mathrm{C}_{\mathrm{m}} & =\text { pitching-moment coefficient } \\ \mathrm{D} & =\text { model diameter, in } \\ \mathrm{L}_{\mathrm{ref}} & =\text { longitudinal reference length, in } \\ \mathrm{L} / \mathrm{D} & =\text { lift-to-drag ratio } \\ \mathrm{M}_{\infty} & =\text { freestream Mach number } \\ \mathrm{P}_{\mathrm{t}} & =\text { tunnel stagnation pressure, psia } \\ \mathrm{q}_{\infty} & =\text { free stream dynamic pressure, psia } \\ \operatorname{ReD}_{\mathrm{D}} & =\text { Reynolds number based on model diameter } \\ \operatorname{Re}_{\infty} & =\text { free stream unit Reynolds number/ft }\end{array}$

* Aerospace Engineer, Aerothermodynamics Branch, MS 408A

$\dagger$ Aerospace Engineer, Aerothermodynamics Branch, MS 408A, Senior Member AIAA.

I Aerospace Engineer, Aerothermodynamics Branch, MS 408A, Associate Fellow AIAA.

$\S$ Aerospace Engineer, Aerothermodynamics Branch, MS 408A, Senior Member AIAA.

** Aerospace Engineer, Flight Dynamics Branch, MS 153, Associate Fellow, AIAA.

$\dagger \dagger$ Aerospace Engineer, Configuration Aerodynamics Branch, MS 407, Member AIAA

It Aerospace Engineer, Configuration Aerodynamics Branch, MS 267, Lifetime Senior Member, AIAA

$\S \S$ Aerospace Engineer, Code AOX, MS 260-1, AIAA Member

*** Aerospace Engineer, Aerothermal \& Flight Mechanics, 2222 Bay Area Blvd, Member, AIAA 
$\mathrm{S}_{\text {ref }} \quad=$ reference area, in $^{2}$

$\mathrm{X}_{\mathrm{mrc}} \quad=\mathrm{X}$ location of moment reference center, in

$\mathrm{Y}_{\mathrm{mrc}}=\mathrm{Y}$ location of moment reference center, in

$\mathrm{Z}_{\text {mrc }} \quad=\mathrm{Z}$ location of moment reference center, in

$\alpha \quad=$ angle of attack, deg

$\beta \quad=$ angle of sideslip, deg

\section{Introduction}

The Apollo-derived Orion Crew Exploration Vehicle (CEV) was part of NASA's now-cancelled Constellation Program to return humans to the moon and other destinations in the solar system. Orion will now serve as the reference vehicle design for the new Multi-Purpose Crew Vehicle (MPCV). The MPCV

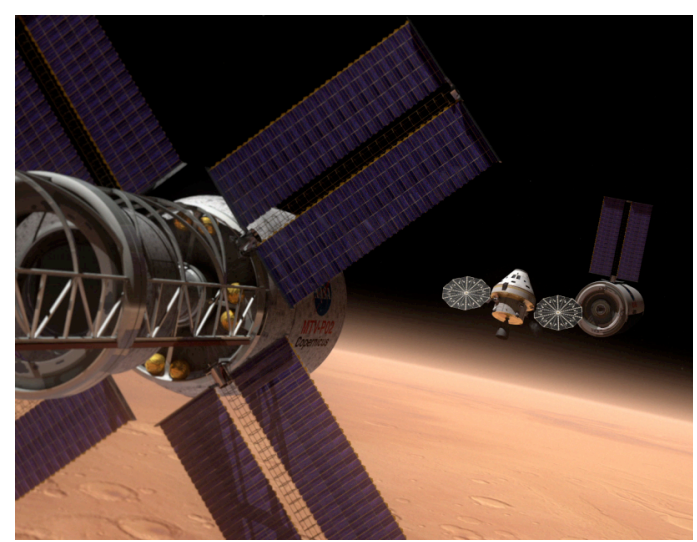

Figure 1. Artist's rendering of the MPCV on a deep space mission.

nearly three times the volume of the Apollo capsules (Fig. 3). This design will shorten development time, reduce reentry loads, and increase landing stability, resulting in a spacecraft ten times safer than the current Space Shuttle, currently scheduled to be retired in 2011 . $^{2}$

An aerodynamic database for the crew module (CM) capsule is required for the development and analysis of flight trajectories, control systems, structural design, and in

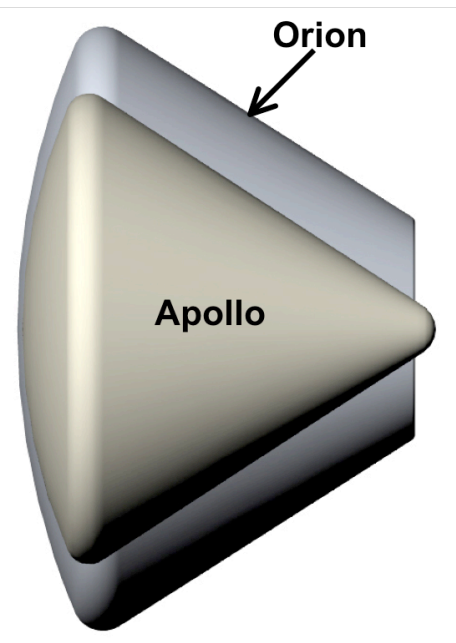

Figure 3. Apollo (with apex cover) and Orion outer-mold-line notional comparison.
(Fig. 1) will serve as the exploration vehicle that will carry the crew to space, provide emergency abort capability, sustain the crew during the space travel, and provide safe re-entry from deep space return velocities. The Orion Crew Module (CM) shape (Figure 2) is similar to the Apollo capsule, as blunt-body, conical spacecraft provide the safest, most economical means of transporting crews to and from space. ${ }^{1}$ With a diameter of approximately 5 meters, the Orion $\mathrm{CM}$ will have

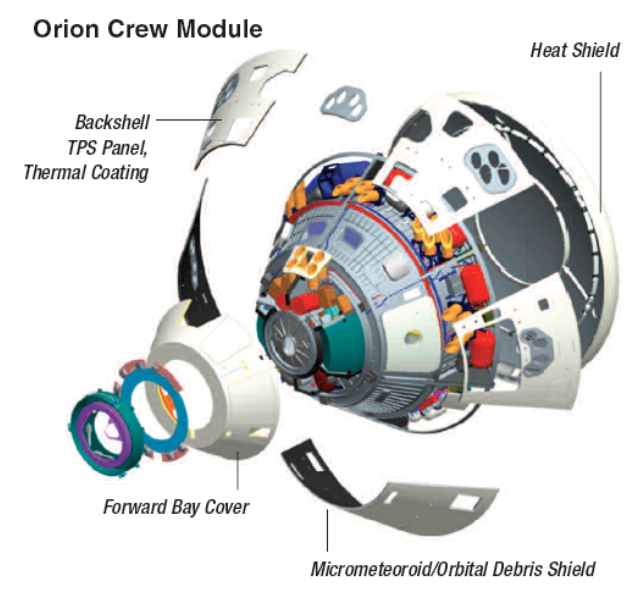

Figure 2. Exploded view of Orion crew module capsule.

conjunction with the aerothermal database, the overall thermal analysis and thermal protection system design. This database must cover nominal return from low-Earth orbit and lunar missions as well as post-separation, ascent abort from the launch vehicle and Launch Abort System (LAS). The database must also capture reaction control system jet interaction increments for associated flight phases.

A strategic wind-tunnel test program has been executed at numerous facilities throughout the country to support several phases of aerodynamic database development. ${ }^{3}$ Static force and moment tests have been done in the subsonic, transonic, supersonic, and hypersonic speed regimes focused on reentry aerodynamics. In the subsonic, transonic 
and supersonic regimes, companion static and dynamic surface pressure data have also been generated. Both discrete pressure and integrated force and moment data is being used to validate existing computational methods so that both computational fluid dynamics (CFD) codes and wind tunnel data may be used synergistically to develop the complete aerodynamic database for the Orion crew module.

\section{Objectives}

Eight CEV Aerosciences Program (CAP) official tests produced static aerodynamic information on the Orion crew module capsule. This paper will present an overview of the wind tunnel test programs, experimental techniques used, and samples of the data collected to-date for the Orion CM configuration. Comparisons will be made to highlight effects of angle of attack, Mach number, Reynolds number, and model support system effects. Deficiencies in the experimental database and proposed future testing will be discussed. As presented in Reference 4, both experimental and computational data were used as inputs to generate the nominal static aerodynamic database coefficients and corresponding coefficient uncertainties. This document is designed as a companion to Reference 4 to provide background information on experimental inputs to aerodynamic database creation. Companion computational data is presented in References 4 and 5.

The test program described herein involved personnel and resources from NASA Langley Research Center (LaRC), NASA Ames Research Center (ARC), NASA Johnson Space Flight Center (JSC), Arnold Engineering and Development Center (AEDC), Lockheed Martin Space Sciences, and Orbital Sciences.

\section{Configuration}

The nominal Orion crew module geometry is based on the Apollo configuration, consisting of a spherical heatshield transitioning to a conical back shell with a truncated base to accommodate docking hardware. Figure 4 shows a detailed schematic with all relevant geometric features dimensioned. The flight geometry is still being developed, and departs from the above axisymmetric, smooth OML, nominal geometry in three main categories:

(1) The nominal backshell angle was widened by $2.5^{\circ}$ to provide more packaging volume for the parachute system. The resulting shape is referred to as the IDAT (Integrated Design Assessment Team) geometry.

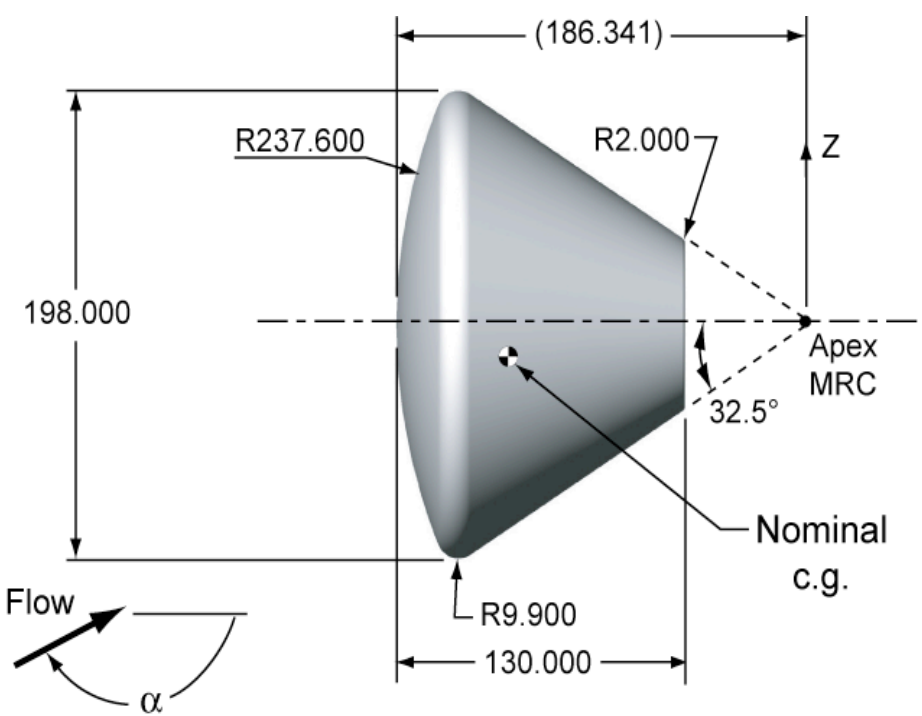

Figure 4. Dimensioned Orion Crew Module.
(2) Based on TPS thickness optimization efforts to minimize vehicle dry weight, the heat shield shape for the flight vehicle will be asymmetric. The shape is designed to be thicker in the higher heating regions such that expected ablation drives the shape closer to the nominal axisymmetric baseline configuration.

(3) Localized geometry variations, including features such as footwells, windows, steps in backshell tile thickness, and other protuberances were not modeled.

Characterizing the effects of these differences has been done primarily via computational efforts, with limited experimental data to be shown in subsequent sections. The aerodatabase addresses these geometry differences by incorporating these additional analyses to adjust nominal coefficients and by using uncertainties to cover expected 
variations. The reader is again referred to Reference 4 for a detailed discussion on database generation using the experimental data presented herein.

\section{Experimental Programs}

Table 1 shows a complete listing of the eight CAP Orion tests producing aerodynamic data on the crew module configuration. These tests were conducted in six different tunnel facilities simulating subsonic to hypersonic flight conditions. All aerodynamic data were generated via typical strain gage force and moment balances chosen to meet test objectives, sized for appropriate loads, and run using best practices for aerodynamic testing. Detailed program test reports exist for each test program and will be referenced below. Only abbreviated information on the facility, overall test objectives, and the physical models are summarized below to accompany the data presentation.

Table 1. List of CAP Tests generating static aerodynamic data for the Orion crew module.

\begin{tabular}{|c|c|c|c|c|c|c|c|}
\hline $\begin{array}{l}\text { CAP } \\
\text { Test }\end{array}$ & $\begin{array}{c}\text { Primary } \\
\text { Objectives }\end{array}$ & Facility & $\begin{array}{c}\text { Model } \\
\text { Scale }\end{array}$ & $\begin{array}{c}\text { OML } \\
\text { Geometry }\end{array}$ & $\begin{array}{r}\text { Support } \\
\text { System }\end{array}$ & $\begin{array}{l}\text { Mach } \\
\text { Range }\end{array}$ & $\begin{array}{c}\text { Model } \\
\text { Attitude }\end{array}$ \\
\hline 03-CA & $\begin{array}{c}\text { CM Static } \\
\text { Aerodynamics }\end{array}$ & $\begin{array}{c}\text { LaRC } \\
\text { UPWT }\end{array}$ & $3.03 \%$ & $\begin{array}{l}\text { CXP- } \\
15000\end{array}$ & $\begin{array}{l}\text { Sting } \\
\text { at } 135^{\circ}\end{array}$ & $1.6-4$ & $\begin{array}{c}140^{\circ} \text { to } \\
170^{\circ}\end{array}$ \\
\hline 05-CA & $\begin{array}{c}\text { CM Static } \\
\text { Aerodynamics }\end{array}$ & $\begin{array}{c}\text { ARC } \\
\text { UPWT }\end{array}$ & $\begin{array}{l}7.66 \% \\
3.03 \%\end{array}$ & $\begin{array}{l}\text { CXP- } \\
15000\end{array}$ & $\begin{array}{l}\text { Sting } \\
\text { at } 135^{\circ}\end{array}$ & $0.3-2.5$ & $\begin{array}{c}142^{\circ} \text { to } \\
172^{\circ}\end{array}$ \\
\hline 09-CA & $\begin{array}{c}\text { CM Static } \\
\text { Aerodynamics }\end{array}$ & $\begin{array}{l}\text { LaRC } \\
\text { M6 }\end{array}$ & $2.02 \%$ & $\begin{array}{l}\text { CXP- } \\
15000\end{array}$ & $\begin{array}{l}\text { Sting at } \\
\text { various } \\
\text { angles }\end{array}$ & 6 & $\begin{array}{l}-5^{\circ} \text { to } \\
185^{\circ}\end{array}$ \\
\hline 18-CD & $\begin{array}{l}\text { CM Dynamic } \\
\text { Aerodynamics }\end{array}$ & $\begin{array}{c}\text { LaRC } \\
\text { TDT }\end{array}$ & $8.6 \%$ & $\begin{array}{l}\text { CXP- } \\
15000\end{array}$ & $\begin{array}{c}\text { Sting } \\
\text { through } \\
\text { model }\end{array}$ & $0.2-1.1$ & $\begin{array}{l}110^{\circ} \text { to } \\
185^{\circ}\end{array}$ \\
\hline $24-\mathrm{AA}$ & $\begin{array}{c}\text { CM/LAT } \\
\text { Separation } \\
\text { Aerodynamics }\end{array}$ & $\begin{array}{c}\text { AEDC } \\
16 \mathrm{~T}\end{array}$ & $7 \%$ & $606 \mathrm{E}$ & $\begin{array}{c}\text { Sting } \\
\text { at } 180^{\circ}\end{array}$ & $0.3-1.2$ & $\begin{array}{c}150^{\circ} \text { to } \\
190^{\circ}\end{array}$ \\
\hline $25-\mathrm{AA}$ & $\begin{array}{c}\mathrm{CM} / \mathrm{LAT} \\
\text { Separation } \\
\text { Aerodynamics } \\
\end{array}$ & $\begin{array}{c}\text { ARC } \\
\text { UPWT }\end{array}$ & $3 \%$ & $606 \mathrm{H}$ & $\begin{array}{l}\text { Sting } \\
\text { at } 180^{\circ}\end{array}$ & $1.6-2.5$ & $\begin{array}{c}152^{\circ} \text { to } \\
182^{\circ}\end{array}$ \\
\hline $27-A D$ & $\begin{array}{c}\mathrm{CM} / \mathrm{LAV} \\
\text { Dynamic } \\
\text { Aerodynamics }\end{array}$ & $\begin{array}{c}\text { LaRC } \\
\text { TDT }\end{array}$ & $8.6 \%$ & $\begin{array}{l}\text { CXP- } \\
15000\end{array}$ & $\begin{array}{c}\text { Sting } \\
\text { through } \\
\text { model }\end{array}$ & $0.2-1.1$ & $\begin{array}{l}0^{\circ} \text { to } \\
360^{\circ}\end{array}$ \\
\hline 61-AA & $\begin{array}{c}\mathrm{CM} / \mathrm{LAT} \\
\text { Separation } \\
\text { Aerodynamics }\end{array}$ & $\begin{array}{l}\text { LaRC } \\
14 \times 22\end{array}$ & $6 \%$ & $\begin{array}{l}\text { CXP- } \\
15000\end{array}$ & $\begin{array}{l}\text { Sting } \\
\text { at } 180^{\circ}\end{array}$ & 0.13 & $\begin{array}{c}140^{\circ} \text { to } \\
190^{\circ}\end{array}$ \\
\hline
\end{tabular}

\section{LaRC 14'x22' LSWT Testing}

CAP Test 61-AA was conducted at the NASA Langley 14'x22' Low Speed Wind Tunnel (LSWT) Facility in Hampton, Virginia. The 14'x22' is a subsonic, closed circuit, single return, atmospheric wind tunnel with an operating envelope of $\mathrm{M}=0.01$ to 0.3 and a maximum unit Reynolds number of $2.1 \times 10^{6} / \mathrm{ft}$. There were two primary objectives of the 61-AA test program: (1) to investigate the Jettison Motor (JM) plume interactions of the Crew Exploration Vehicle (CEV) Launch Abort System (LAS) on the aerodynamic performance and stability of the crew module and Launch Abort Tower (LAT), and (2) to investigate the proximity aerodynamic effects of the Launch Abort Tower (LAT) separation from the CM. Thus, baseline aerodynamic data were taken on the CM configuration. A 6\%-scale, aluminum model (Figure 5) was tested at dynamic pressure of $\mathrm{q}_{\infty}=25 \mathrm{psf}\left(\mathrm{M}_{\infty}=0.13\right)$, angles of attack from $190^{\circ}$ to $140^{\circ}$, 


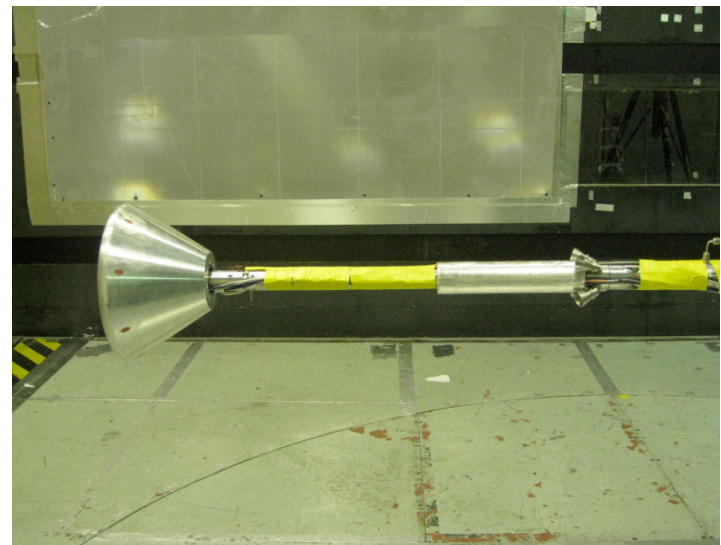

Figure 5. 61-AA 6\%-scale CM model in LaRC 14'x22' LSWT.

and angles of sideslip from $-10^{\circ}$ to $10^{\circ}$. The Task Mark X balance from the Oran Nicks Low Speed Wind Tunnel was used for the CM model. Full details of the 61-AA test program are found in Reference 6.

\section{$\underline{\text { LaRC TDT Testing }}$}

The facility used for CAP Tests 18-CD and $27-\mathrm{AD}$ to measure the pitch damping characteristics of both the crew module and the launch abort vehicle was the NASA Langley Research Center Transonic Dynamics Tunnel (TDT). The TDT is a closed-circuit, continuous flow, variable pressure wind tunnel with a $16-\mathrm{ft}$ square test section with cropped corners. The tunnel is capable of using either air or heavy gas R$134 \mathrm{a}$ as the test medium. The tunnel can operate up to a Mach number of 1.2 and is capable of maximum unit Reynolds numbers of about $3 \times 10^{6} / \mathrm{ft}$ in air and $10 \times 10^{6} / \mathrm{ft}$ in $\mathrm{R}-134 \mathrm{a}$. The tunnel may also be operated at stagnation pressures from near vacuum $\left(\mathrm{P}_{\mathrm{t}}=0.025\right.$ atms) to atmospheric and at dynamic pressures up to $330 \mathrm{psf}$ in air and $550 \mathrm{psf}$ in R-134a. The subsonictransonic dynamic stability of the model was quantified by employing the forced oscillation and free-to-

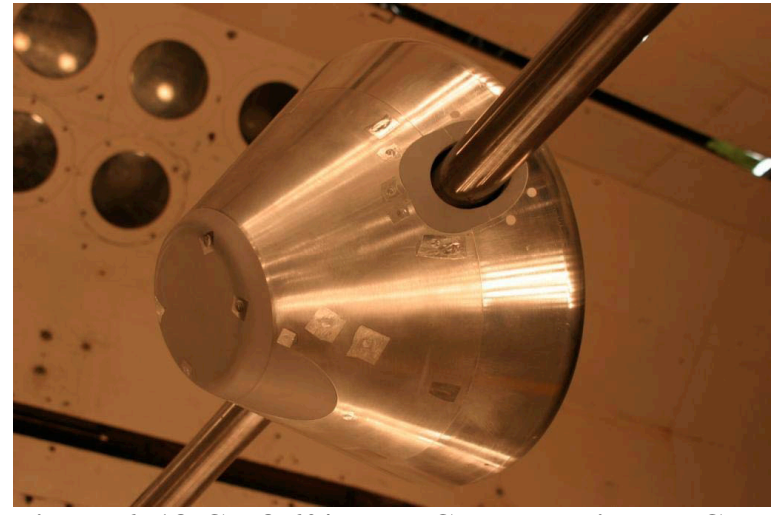

Figure 6. 18-CD 8.6\%-scale CM model in LaRC TDT.

in References 7 and 8. pitch techniques in the TDT. Static force and moment data were also measured to support the dynamic aero data. An 8.6\%-scale (17 in. diameter) aluminum, steel, and polycarbonate model (Figure 6) was tested over a Mach range of 0.1 to 1.1 and an angle-of-attack range of $110^{\circ}-185^{\circ}$ for $18-\mathrm{CD}$ and $0^{\circ}-360^{\circ}$ for $27-\mathrm{AD}$ using the NASA LaRC 1635 balance. Figure 6 shows that the model was mounted on a shaft entering the model from the sides. This mounting arrangement is preferred for acquiring large amplitude dynamic data as the sting entry is the same for all $\alpha$ and the oscillation amplitude is not limited by how the sting is mounted. Obviously, sting interference was observed for static data and thus was only used primarily for CFD validation. Full details of the $18-\mathrm{CD}$ and $27-\mathrm{AD}$ test programs are found

\section{ARC UPWT Testing}

Subsonic through supersonic aerodynamic data was obtained for the Orion crew module in the Unitary Plan Wind Tunnel (UPWT) at NASA Ames Research Center (ARC). The facility is a closed-circuit, variable-pressure, continuous-flow wind tunnel with two operational test sections. The $11 \times 11$-Foot transonic leg can be operated over a Mach number range of 0.2 to 1.45 , and at total pressures up to 32 psia. Operating air temperatures can range from $80^{\circ} \mathrm{F}$ to $150^{\circ} \mathrm{F}$, with a standard operating temperature of approximately $100^{\circ} \mathrm{F}$. The tunnel can reach a maximum unit Reynolds number of

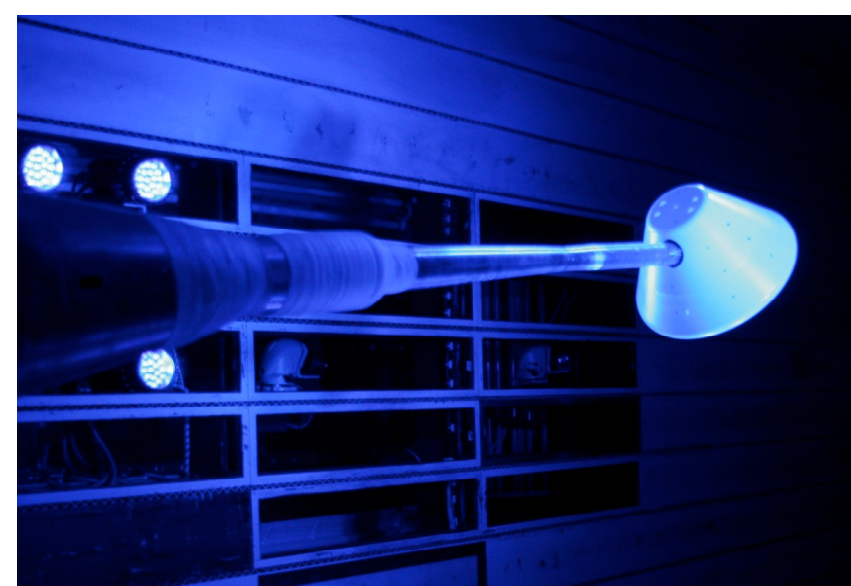

Figure 7.5-CA 7.66\%-scale CM model in ARC UPWT. 
$9.6 \times 10^{6} / \mathrm{ft}$ at $\mathrm{M}=1.2$. Over the transonic range $(0.7 \leq \mathrm{M} \leq 1.4)$ the tunnel can reach a unit Reynolds number of $8.0 \times 10^{6} / \mathrm{ft}$. The $9 \times 7$-Foot supersonic leg can be operated over a Mach number range of 1.5 to 2.5 , and at total pressures of up to $26 \mathrm{psia}$, and with similar operating temperatures to the $11 \times 11$-Foot leg. The maximum achievable Reynolds number is primarily limited by available compressor power of $176 \mathrm{MW}$. A unit Reynolds number of $5.0 \times 10^{6} / \mathrm{ft}$ can be reached over most of this leg's Mach range.

CAP Test 5-CA was the main source of experimental aerodynamic data used to build the CM aerodynamic database from Mach 0.3 to Mach 2.5 because of its Mach and Reynolds number range. A $7.66 \%$-scale aluminum model (Figure 7) was tested at nominal angles of attack from $140^{\circ}$ to $170^{\circ}$ at

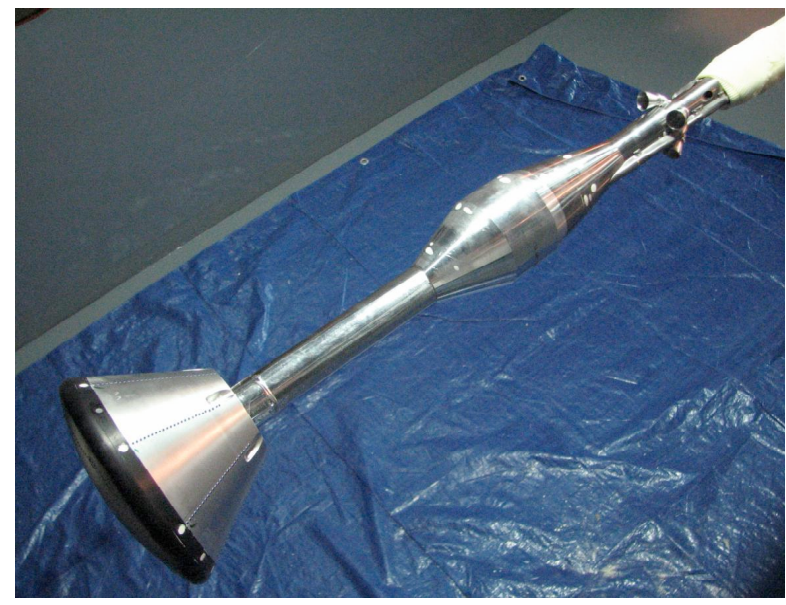

Figure 8. 25-AA 3\%-scale CM model in ARC UPWT. Reynolds numbers based on model diameter over $7 \times 10^{6}$. Force and moment data were obtained using the Task 1.5" Mk 13A balance. To supplement balance data, a significant effort was made in the 5-CA program to obtain aerodynamic data via integrated pressure sensitive paint (PSP). The heat-shield section was instrumented with 126 static pressure taps in three radial and two circumferential rows as well as 11 dynamic pressure tranducers. Static pressures provide anchor points for the PSP data as well as for companion data for CFD validation. A $3.03 \%$-scale CM model (described in a subsequent section) was also tested as part of Test 5-CA program to provide uncertainty information. Full details of the 5CA test program are found in Reference 9.

Crew module data was also obtained in the UPWT 9x7-ft test section as part of CAP Test 25-AA. The primary objective of the 25-AA test program was to determine the aerodynamic characteristics of the CM and LAT, while in proximity to one another and while under the influence of jet interaction effects from the Jettison Motor (JM) plumes, in simulating the post-abort LAT jettison event. As part of the proximity database, isolated CM data were obtained using the Ames MK IV Task Balance in an aluminum 3\%-scale model (Figure 8) from Mach 1.6 to 2.5 for angles of attack from $152.5^{\circ}$ to $182.5^{\circ}$ at Reynolds Numbers based on model diameter of $1 \times 10^{6} / \mathrm{ft}$ to $1.3 \times 10^{6}$. The CM OML for this test was an asymmetric heatshield with the IDAT backshell, and thus used to characterize this off-nominal geometry. Full details of the 25-AA test program are found in Reference 10.

\section{AEDC 16T Testing}

A companion proximity test to $25-\mathrm{AA}$ was CAP Test 24-AA conducted in the Arnold Engineering and Development Center's (AEDC) Tunnel 16T. The 16-foot-square, 40-foot long test section can be tested at Mach numbers from 0.05 to 1.60 . Pressure in the test section can be varied to simulate unit Reynolds numbers from approximately $0.03 \times 10^{6} / \mathrm{ft}$ to $7.3 \times 10^{6} / \mathrm{ft}$. Test objectives were the same as Test 25-AA, but data were obtained on $7 \%$-scale aluminum models (Figure 9) at subsonic and supersonic conditions. As part of the proximity database, isolated CM data were obtained on an asymmetric heatshield configuration using the LaRC 2043 balance from Mach 0.3 to 1.2 for angles of attack from $150^{\circ}$ to $190^{\circ}$. Full details of the 24-AA test program are found in Reference 10.

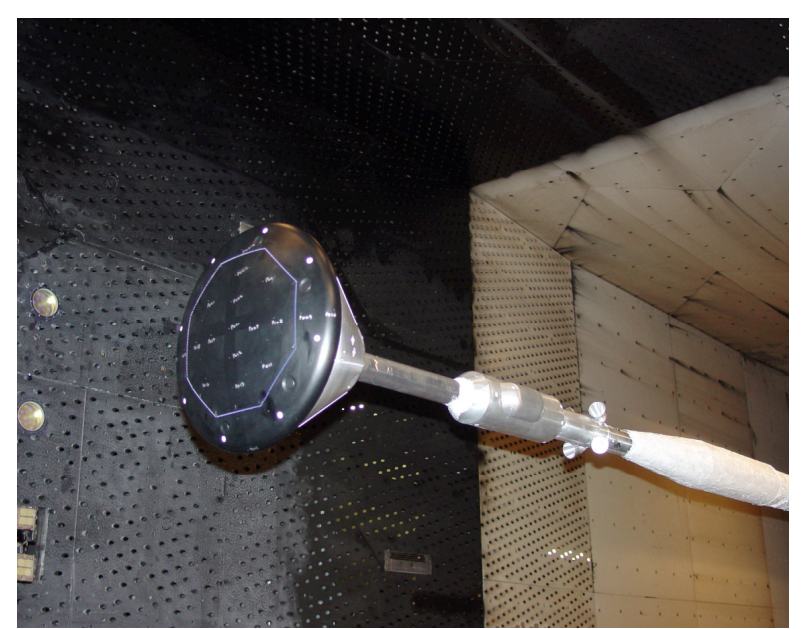

Figure 9. 24-AA 7\%-scale CM model in AEDC 16T Tunnel. 


\section{LaRC UPWT Testing}

The first dedicated crew module aerodynamic testing was conducted in Langley Unitary Plan Wind Tunnel (UPWT) at NASA Langley Research Center (LaRC) in CAP Test 3-CA. The LaRC UPWT is a closed-circuit, continuous-running, pressure tunnel with two test sections that are nominally $4 \mathrm{ft}$ by $4 \mathrm{ft}$ in cross section and 7-ft long. The stagnation pressure can be varied up to a maximum of approximately 50 psia in Test Section I and approximately 100 psia in Test Section II. The Mach number range is nominally 1.5 to 2.86 in Test Section I and 2.3 to 4.63 in Test Section II, with tunnel stagnation temperatures

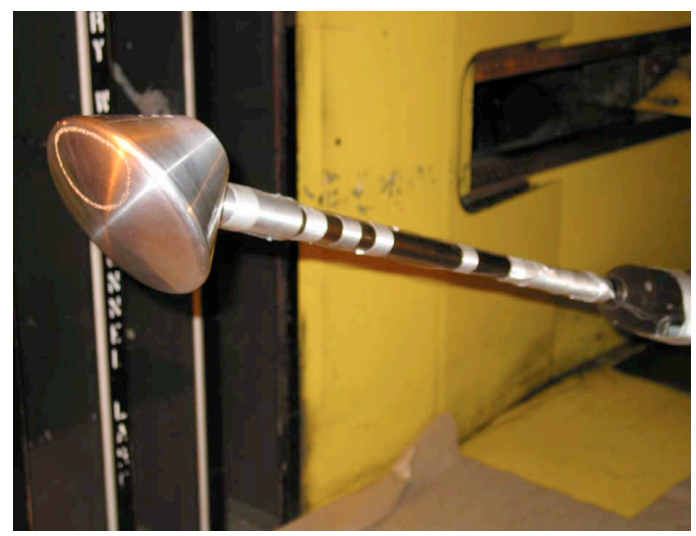

Figure 10. 3-CA 3.03\%-scale CM model in LaRC UPWT. nominally $125^{\circ} \mathrm{F}$ and $150^{\circ} \mathrm{F}$ for each test section, respectively. Unit Reynolds numbers from $1.0 \times 10^{6} / \mathrm{ft}$ to $6.0 \times 10^{6} / \mathrm{ft}$ can be run routinely with a capability to reach $7.0 \times 10^{6} / \mathrm{ft}$ on a transient basis. CAP Test 3-CA was the sole source of experimental aerodynamic data used to build the $\mathrm{CM}$ aerodynamic database from Mach 3.0 to 4.0. Data acquired from Mach 1.6 to 2.5 were used for comparison with the aforementioned 5-CA data. A 3.03\%-scale aluminum model (Figure 10) was tested at nominal angles of attack from $140^{\circ}$ to $170^{\circ}$ at Reynolds Numbers based on model diameter up to $1.5 \times 10^{6}$. Data were obtained using the LaRC 2049 balance. Due to size constraints, a dedicated identical scale pressure model was tested (CAP Test 7-CA) to provide companion static pressure data for CFD validation. Prior to these quantitative aerodynamic and pressure tests, a qualitative transition study, CAP Test 1-CA,' was conducted in the LaRC UPWT on a 3.03\%-scale model. This test employed both temperature sensitive paint (TSP) and Infrared Thermography (IRT) to qualitatively examine both clean and gritted models to gain insight into windward boundary layer state in the supersonic regime. Full details of the 3-CA test program are found in Reference 11. Reference 12 provides an overview of all CM testing in the LaRC UPWT, including results from CAP Tests 1-CA, 3$\mathrm{CA}$, and 7-CA.

\section{LaRC 20-Inch Mach 6 Testing}

CAP Test 9-CA was the sole source of hypersonic experimental aerodynamic data used to build the CM aerodynamic database. The test program was conducted in Langley's 20-Inch Mach 6 Air Tunnel, which is a conventional blow-down hypersonic tunnel that uses heated, dried, and filtered air as the test gas. Typical operating conditions for the tunnel are stagnation pressures from 30 to 500 psia, stagnation temperatures from $800^{\circ} \mathrm{R}$ to $1000^{\circ} \mathrm{R}$, free stream Mach number from 5.8 to 6.1 , free stream unit Reynolds numbers from $0.5 \times 10^{6} / \mathrm{ft}$ to $8.0 \times 10^{6} / \mathrm{ft}$, and a free stream and post normal-shock ratio of specific heats (gamma, $\gamma$ ) of 1.4. Nominal run time is approximately 60 to 120 seconds, although longer runs times are possible.

Six 4-inch diameter aluminum models (Figure 11) were used to cover the angle-of-attack range from $-5^{\circ}$ to $185^{\circ}$. The balance entered the model at various offset angles such that the sting was relatively hidden in the wake flow in an attempt to minimize support interference. Each model covered a $40^{\circ}$ angle of attack range, with $10^{\circ}$ overlap between each setup. A seventh model provided an additional offset angle at approximately the trim angle of attack $\left(155^{\circ}\right)$. The seven models are identical except for the balance entry angle. Although the nominal CEV geometry does not include an apex cover (covering the flat-faced end), one was fabricated to closely represent the Apollo block I geometry for comparison to previous Apollo data. The primary instrumentation was the Langley HCF-14 balance. All data obtained

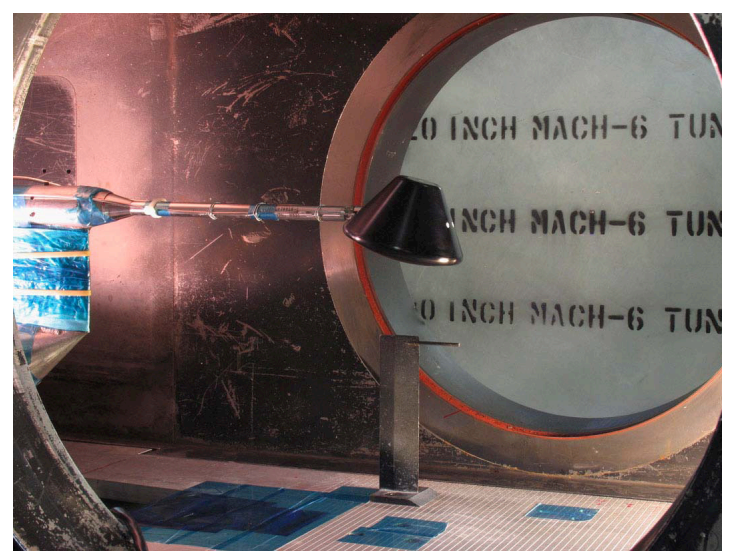

Figure 11. 9-CA 2.02\%-scale CM model in LaRC 20-Inch Mach 6 Tunnel. 
were at Mach 6 conditions with a Reynolds Number based on model diameter of $1.5 \times 10^{6}$. Full details of the 9-CA test program are found in Reference 13.

\section{Test Techniques}

The primary goal for all of the aforementioned tests was acquisition of quantitative aerodynamic data. Many tests used additional quantitative and qualitative techniques to provide companion surface and flow field information to compliment the static aerodynamic data. This section serves to make the reader aware of the array of experimental techniques employed for crew module testing and does not seek to provide indepth analyses of images presented herein. The reader is referred to CAP Test reports for a thorough discussion of all results. Table 2 shows a summary of supplemental techniques used for each CAP test program. All experimental test techniques are described below.

Table 2. Summary of supplemental test techniques employed for CAP CM Tests.

\begin{tabular}{|c|c|c|c|c|c|c|}
\hline CAP Test & Pressure & Schlieren & PSP & IRT & TSP & Oil Flow \\
\hline 01-CA & & & & X & X & \\
\hline 03-CA & X & X & & & & \\
\hline 05-CA & X & X & X & & & \\
\hline 09-CA & & X & & & & X \\
\hline 18-CD & & X & & & & \\
\hline 24-AA & X & X & & & & \\
\hline 25-AA & & X & & & & \\
\hline 27-AD & & X & & & & \\
\hline 61-AA & $\mathrm{X}$ & & & & & \\
\hline
\end{tabular}

Aerodynamic Measurements

For all wind tunnel models, three aerodynamic forces and three aerodynamic moments were measured using a standard 6-component strain-gage balance. All balances were fabricated from stainless steel and sized for the expected load range. For six of the test programs, data were taken in a pitch-pause mode and corrected real-time for support system deflection under loading. Tests 24-AA and 25-AA used a continuous sweep data collection technique. Wherever possible static pressure measurements were made in and around the sting-body interface, and the aerodynamic data were corrected for sting effects. Wind-off balance readings were monitored before and after each run, and balance components were monitored during tunnel runs for drift caused by thermal gradients across the balance gages. Hysteresis checks were done by comparing ascending and descending pitch sweep data, and within-test repeatability was addressed by doing selected repeat runs through the test matrix. Observed variations were compared to quoted balance accuracies for all six components based on the $\pm 95 \%$ confidence level from balance calibration reports. Aerodynamic data obtained from differently scaled models in multiple wind tunnel facilities were analyzed to obtain the most rigorous estimate of overall uncertainty.

\section{Pressure Measurement}

All static pressure measurements on the model surface, in proximity to the sting, and in the model cavity were made using a commercially available electronically scanned pressure (ESP) module. Miniature electronic pressure scanners are differential pressure measurement units consisting of an array of silicon piezoresistive pressure sensors, one for each pressure port. When there was sufficient model internal volume, the ESP module was mounted on or near the balance block inside the model cavity. Flexible pressure tubing was used to connect each surface tap and cavity pressure line to specified ESP module ports. For smaller scale models, tubes were run either internal or external to the main support sting and connected to offboard ESP modules.

Dynamic surface pressures were obtained on the windward face of the largest scale CM model for subsonic, transonic, and supersonic test conditions. Discrete piezoresistive sensors mounted in the model surface, coupled with appropriate amplifiers, filters, and high-speed data acquisition equipment were used to determine the spectral characteristics of local pressure measurements over the range of test conditions. 
Care was taken to determine sources of fluctuation that were artifacts of the facility and the model installation rather than model flow phenomena.

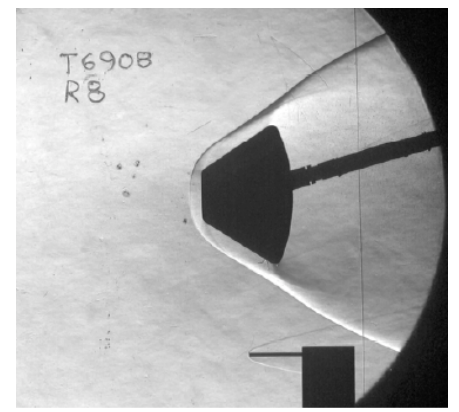

(a) Model $\alpha=-1^{\circ}$

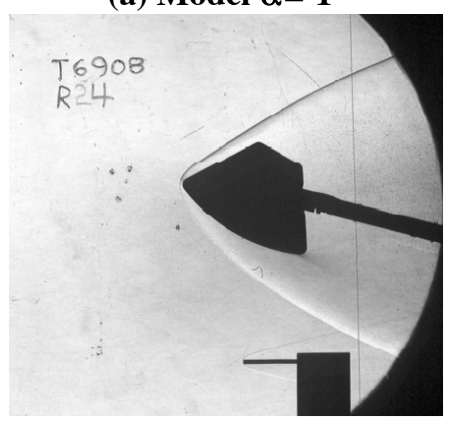

(d) Model $\alpha=119^{\circ}$

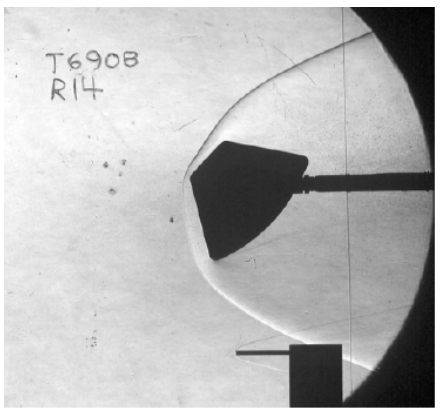

(b) Model $\alpha=44^{\circ}$

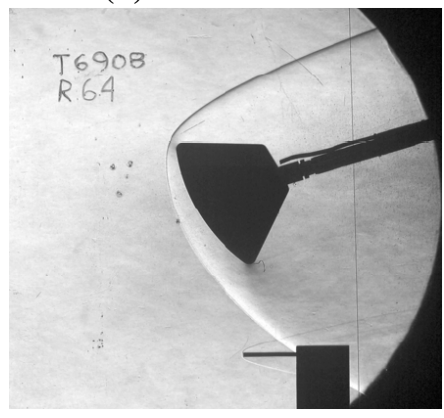

(e) Model $\alpha=149^{\circ}$

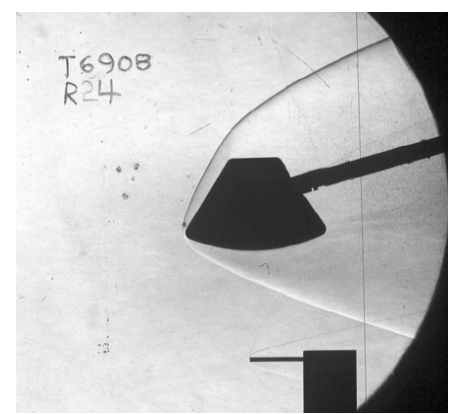

(c) Model $\alpha=89^{\circ}$

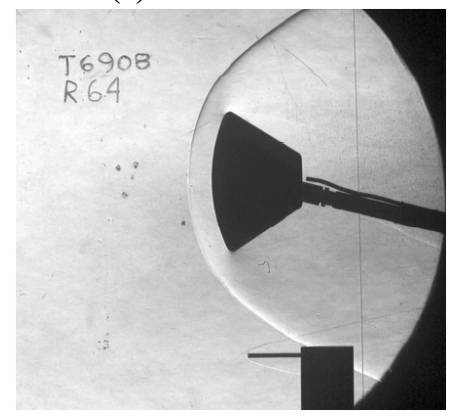

(f) Model $\alpha=179^{\circ}$

Figure 12. Examples of Schlieren photographs of the crew module from the LaRC Mach 6 tunnel over a $180^{\circ}$ angle-of-attack range.

\section{$\underline{\text { Schlieren Flow Visualization }}$}

Standard Schlieren systems use light from a single collimated source focused through a lens on a knife-edge to visualize density variations in the flow field around a test article. Corresponding variations in refractive index caused by density gradients in the fluid distort the collimated light. The result is a set of lighter and darker regions corresponding to positive and negative fluid density gradients in the direction normal to the knife-edge. Thus salient flow field features such as shock-waves, flow separation/reattachment, and jet plume trajectory/impingements can be visualized. Figure 12 shows examples of Schlieren photographs of the crew module tested at Mach 6 test conditions over a $180^{\circ}$ angle-of-attack range.

Pressure Sensitive Paint

Pressure Sensitive Paint (PSP) allows non-intrusive global surface pressure measurements to be made using an optical detector (camera). The surface is coated, typically via spray application, with PSP that is made up of a luminescent probe molecule held in an oxygen permeable binder. The probe molecule is chosen such that its luminescence is quenched by oxygen. When the model is being tested in the wind tunnel, ultraviolet light from a high intensity LED lamp is beamed onto the surface, and the molecules fluoresce in a visible light wavelength. The intensity of the visible light is proportional to the amount of oxygen above the coating. Higher pressures cause more
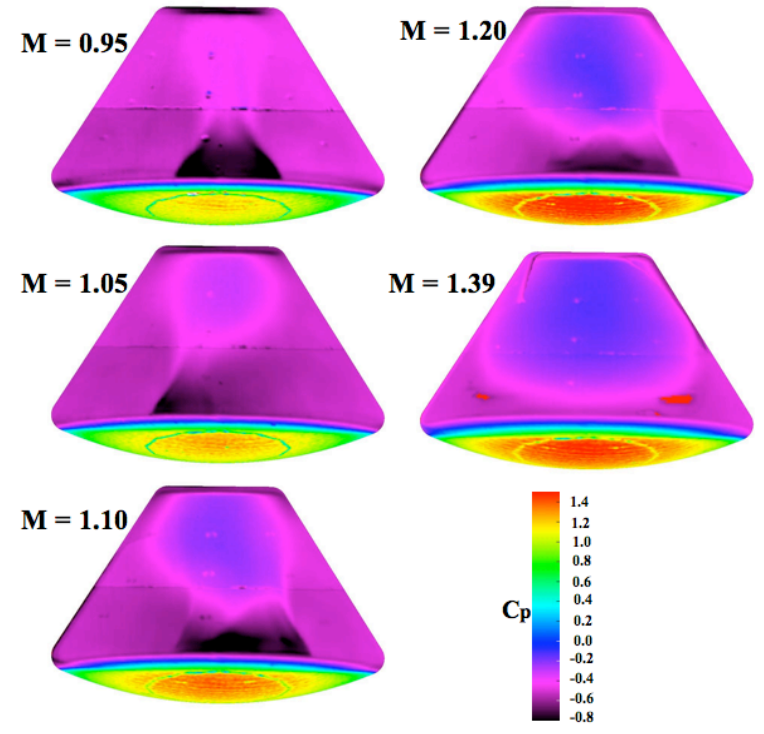

Figure 13. PSP images obtained for the CM tested at transonic conditions in the ARC UPWT. 
oxygen molecules to permeate the binder in the paint, resulting in a dimmer phosphorescence. This change of intensity can be converted to a quantitative change in pressure via an appropriate calibration. Computeraided photography can be used to produce false-color images, where the color range corresponds to the pressure variations. Figure 13 contains PSP images obtained for the crew module tested at transonic conditions in the ARC UPWT showing the change in surface pressure distribution with Mach number.

\section{Infrared Thermography}

Infrared (IR) thermography is a non-intrusive video-based, radiometric measurement technique capable of obtaining real-time global surface temperature data based on blackbody radiation theory. All objects emit radiation in the $0.1 \mathrm{~mm}-100 \mathrm{~mm}$ region of the spectrum according to Planck's law due solely to their thermal energy. Detection of this emitted radiation, and an understanding of how an object radiates/absorbs thermal energy with its environment, makes this an excellent tool for the remote detection of surface temperature distributions. The amount of radiation emitted by an object increases with temperature; therefore, thermography allows one to see variations in temperature. Emissivity is a measure of how effective a real object is at absorbing/emitting radiation while at a given temperature when compared to an ideal (black body). In order to get the best possible thermal signatures from this wind tunnel model, it was necessary to apply a high emittance, low thermal conductivity and low specific heat coating to the model surface to improve these surface properties for infrared-based temperature measurements. The colored images in Figure 14 were obtained using IR thermography for two different Reynolds numbers with and without boundary layer trips. These images show strong evidence of flow transition on the heat shield with increasing Reynolds number and/or the addition of boundary layer trips.

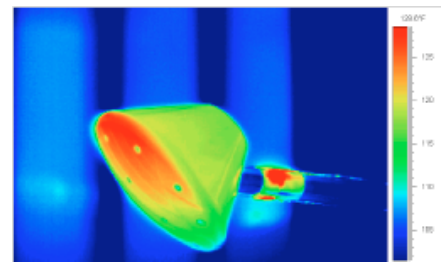

(a) Low Reynolds number, no trips

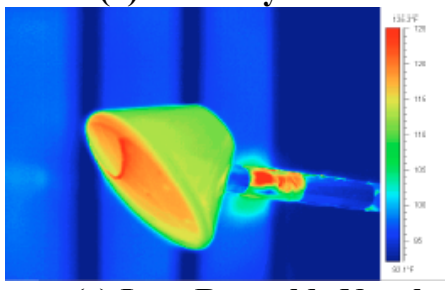

(c) Low Reynolds Number, with trips

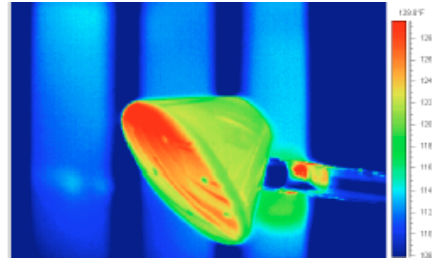

(b) High Reynolds number, no trips
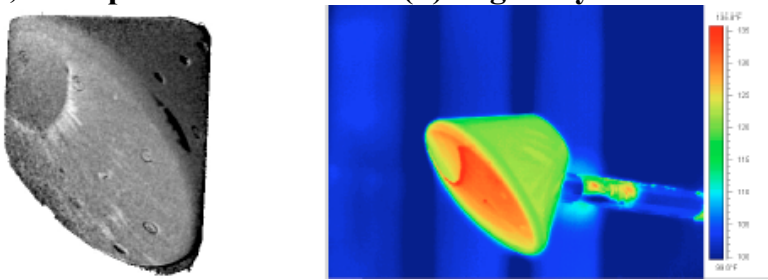

(d) High Reynolds number, with trips

Figure 14. IR and TSP qualitative temperature images of crew module model with and without grit in LaRC UPWT.

\section{Temperature Sensitive Paint}

Temperature Sensitive Paint (TSP) thermography is a well-proven, non-intrusive technique for measuring surface heat flows and has been applied to investigate aerodynamic heating, and detect flow transition, separation, and reattachment. TSP is analogous to PSP in that it is typically constructed by dispersing luminescent probe species within a suitable polymeric binders or paints. Whereas PSP uses an oxygen permeable binder to measure luminescence decrease with increasing oxygen condition, TSP binders are generally constructed using an oxygen impermeable binder. Thus the luminescence change is directly related to only changes in temperature, with increasing temperature resulting in a decrease in luminescence. The black-and-white images in Figure 14 were generated using TSP and are companions to the IR images to see qualitative heating and corresponding transition effects of Reynolds number and boundary layer trips.

\section{Oil Flow Surface Visualization}

For hypersonic testing, surface streamlines were visualized using an oil flow technique. To facilitate faster injection and retraction motion into the blowdown facility, these runs were made using a dummy balance. A mixture of silicone oil and white zinc oxide pigment were mixed together and then 
applied onto the model in a speckled pattern. The tunnel is started and brought to the proper test conditions, the model is injected, a flow pattern is allowed to develop, and then the model is retracted. Photographs were taken post-run. Examples of the oil flow technique on the $\mathrm{CM}$ configuration are seen in Figure 15.

\section{Boundary Layer Tripping}

Figure 16 shows expected flight Reynolds Numbers for a range of $\mathrm{CM}$ trajectories as a function of Mach number. Due to traditional facility limitations, experimental data could only be obtained for Reynolds numbers that were significantly lower than predicted flight values. Although extensive transition studies could not be conducted for these test programs, flows were expected to be laminar for these low Reynolds number conditions, and thus trips were applied to models tested at subsonic, transonic, and supersonic conditions in hopes of simulating the turbulent boundary layers expected in flight.

Using theoretical, experimental,
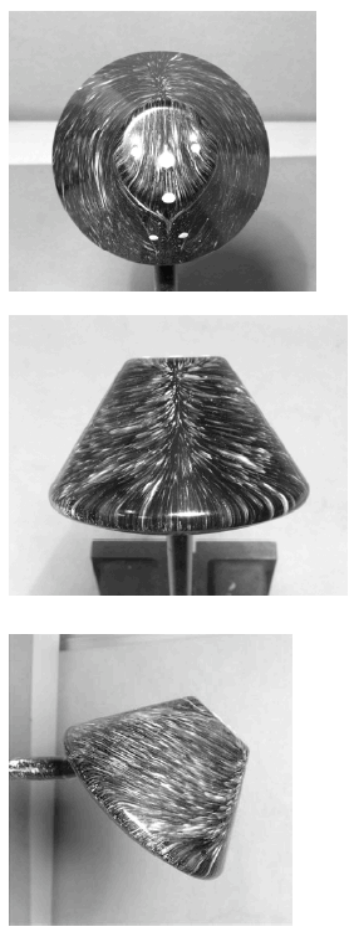

Figure 15. Oil Flow Examples of Crew Module model tested in LaRC Mach 6 tunnel.
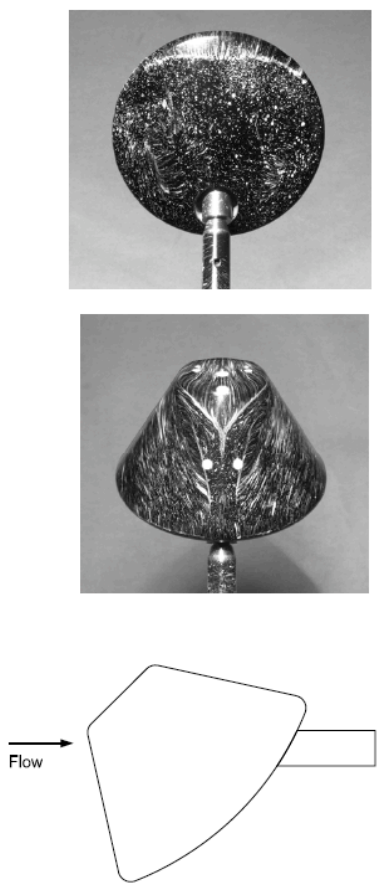

and computational methods, trips were located and sized specifically for each model's test conditions. The reader is referred to individual test reports for exact details and sizing methodologies. The general philosophy was to locate an oval/polygonal ring of trip grit/dots around the model stagnation point the location of which was a function of angle of attack. Trip heights were primarily a function of Mach number. Each Mach number and angle of attack yielded a different optimized grit pattern and grit size. Thus the grit pattern used on each model represented a compromise to capture the range of stagnation points, sized conservatively in attempt to trip all Mach numbers. Figure 17 show examples of grit and dot patterns used

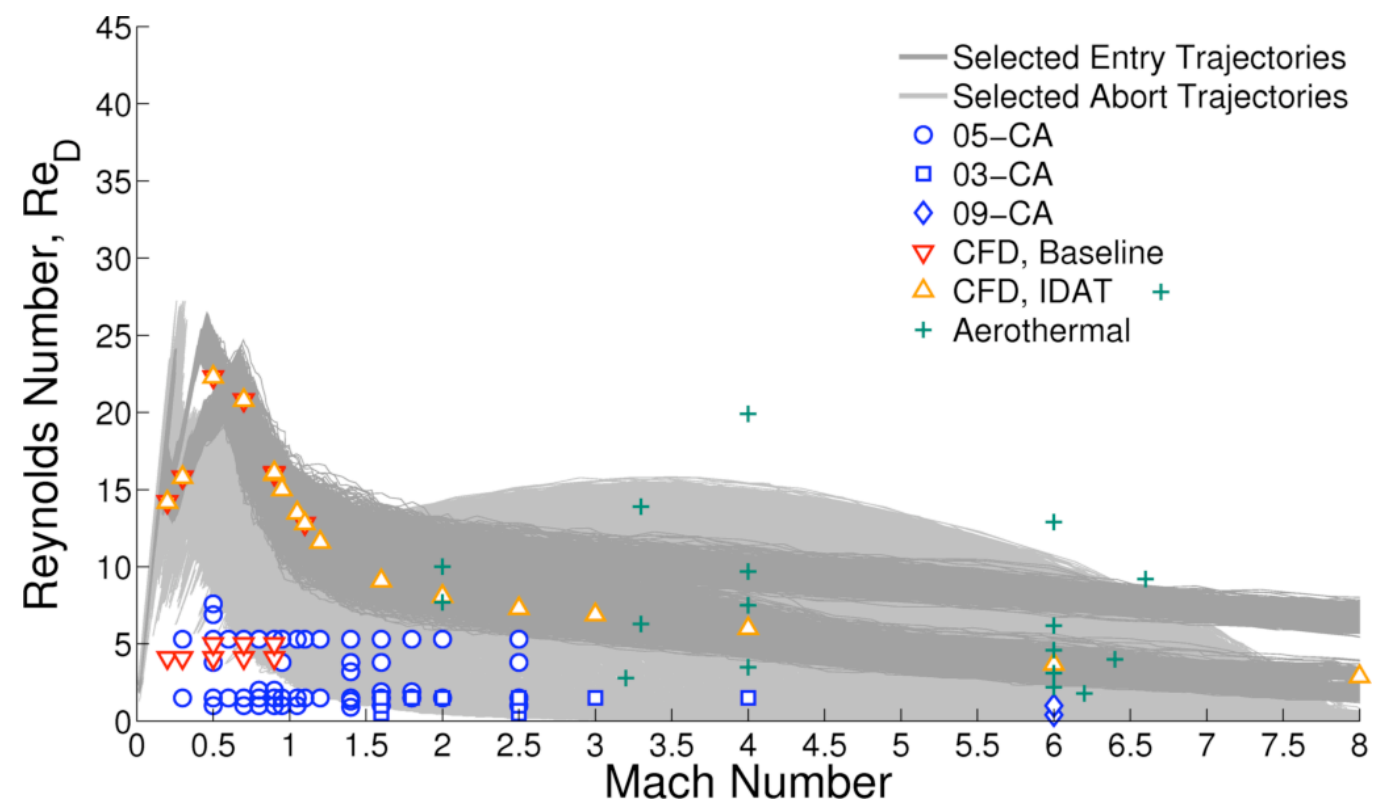

Figure 16. Reynolds number vs. Mach number for a range of nominal and abort trajectories and supporting experimental and computation data. 

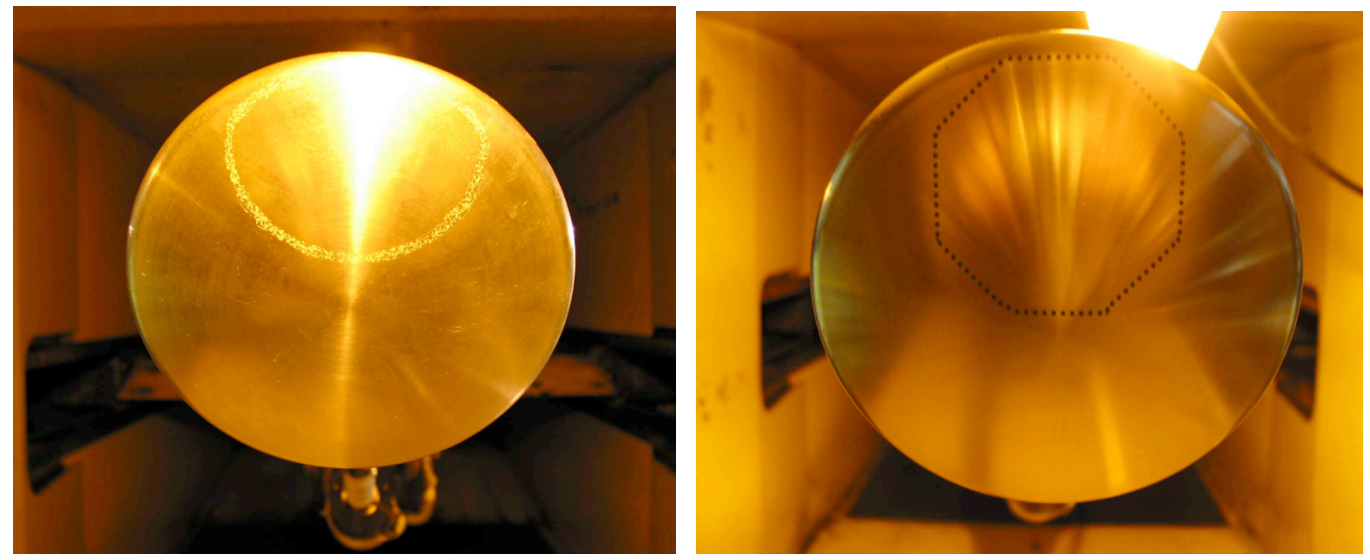

Figure 17. Examples of trip grit and trip dot patterns on the windward heat shield of two Crew Module models tested at supersonic conditions.

for supersonic testing over the angle of attack range of $140^{\circ}$ to $170^{\circ}$. Test 1-CA used both TSP and IR to qualitatively examine trip effects in the supersonic range and test 5-CA used PSP in the subsonic and transonic regimes.

VI. Results

Overview

As shown in Table 1, aerodynamic data were obtained for the CM configuration in eight wind tunnel tests from supersonic to hypersonic test conditions. Sample longitudinal data are presented from all tests to highlight general test and data characteristics. The static aerodynamic database was created using data from the three dedicated crew module tests, and thus the effects of Mach and Reynolds number will be explored in greater detail for these three sets. All data are shown in coefficient form using appropriately scaled reference dimensions from Table 3 and the aerodynamic coordinate system shown in Figure 18. Summary information on data repeatability will also be presented.

Table 3. Crew module reference dimensions.

\begin{tabular}{|c|c|c|}
\hline Constant & Symbol & Full-Scale Value \\
\hline Vehicle Diameter & $\mathrm{D}$ & $16.5 \mathrm{ft}(5.0 \mathrm{~m})$ \\
\hline Reference Length & Lref & $16.5 \mathrm{ft}(5.0 \mathrm{~m})$ \\
\hline Reference Area & Sref & $213.8 \mathrm{ft}^{2}\left(19.6 \mathrm{~m}^{2}\right)$ \\
\hline Moment Reference, X & Xmrc & $10.74 \mathrm{ft}(3.26 \mathrm{~m})$ \\
\hline Moment Reference, Y & Ymrc & 0 \\
\hline Moment Reference, Z & Zmrc & $-0.43 \mathrm{ft}(-0.13 \mathrm{~m})$ \\
\hline
\end{tabular}

General data characteristics

Figures 19-21 present a sampling of longitudinal aerodynamic data in the subsonic, supersonic and hypersonic flow regimes generated from the range of models, facilities, and test programs described in preceding sections. Some data corresponds to ITAR-controlled configurations, thus scales have been removed for subsonic and supersonic test conditions. All data are plotted as a function of model angle of attack. Symbols represent the discrete angles at which data were taken. Curves shown on these plots are linear connections of individual data points. Legends indicate from which test program the data were taken, as well as the corresponding Reynolds number based on model diameter. Pitching moment data from all wind tunnel tests have been reduced about a common center of gravity of location, but this location should not be viewed as a precise value for the final flight vehicle.

Subsonic Data: Figure 19 shows data collected on multiple crew module models at $\mathrm{M}_{\infty}=0.5$ from tests 5-CA, 24-AA, and 27-AD over a range of Reynolds numbers. Data values exhibit a wide span for all 

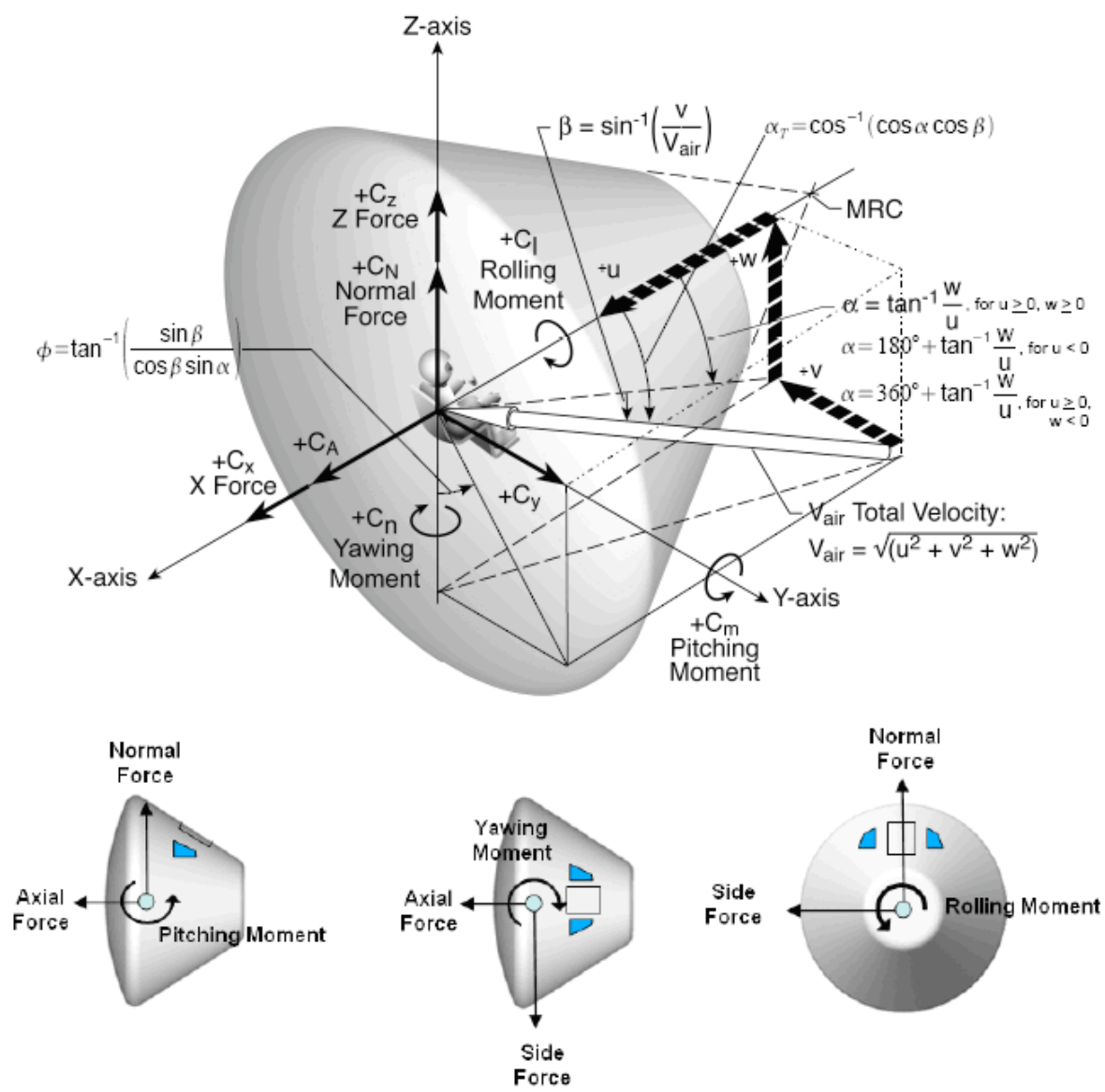

Figure 18. Crew Module aerodynamic coordinate system.

longitudinal coefficients and this range is attributable to several factors. Reynolds number effects will be discussed in a subsequent section, but tests were run up to the highest allowable Reynolds number based on facility, model, or instrumentation limitations. Test 5-CA afforded the largest range of $\mathrm{Re}_{\mathrm{D}}$, but even at the highest Reynolds numbers test conditions, wind tunnel data are deficient by a factor of 3 or greater from entry flight trajectory estimates at Mach 0.5 (Figure 16). For database population the highest Reynolds number data was chosen, but Reynolds number deficiency is recognized as the largest limitation in the available subsonic data sets and a source of significant uncertainty in this speed regime. ${ }^{4}$ For this reason a high-Reynolds number aerodynamic test is planned for the end of 2011 in NASA Langley's National Transonic Facility. Data generated via dynamic testing was expected to have large sting-interference effects due to the horizontal sting arrangement (shown in Figure 6), and thus static CM data from these tests (27$\mathrm{AD}$ shown in Figure 19) was used for code validation only. In addition to low $\mathrm{Re}_{\mathrm{D}}$ test conditions and a sting exit angle and geometry not optimized for this angle of attack range, jettison motor interference testing in AEDC used an asymmetric heatshield and thus crew module data from test 24-AA was used to estimate asymmetry increments rather than create baseline aerodynamic coefficients. Despite the variation in pitching moment coefficient values, all data sets show a stable configuration across the angle of attack range. Lift and drag coefficient curves exhibit similar slopes over most of the angle of attack range.

Supersonic Data: Figure 20 shows data collected on multiple crew module models at $\mathrm{M}_{\infty}=1.6$ from

tests 3-CA, 5-CA, and 25-AA over a range of Reynolds Numbers. There is much less variation with $\mathrm{Re}_{\mathrm{D}}$ than for subsonic conditions, but sizable deltas are still observed between some of the curves, most notably for 25-AA data. The 25-AA model had both an asymmetric heat shield and the IDAT backshell angle, as well as a sting exit angle and geometry not optimized over this angle of attack range. The highest Reynolds number conditions from test 5-CA were used as primary source of experimental data for database construction. 


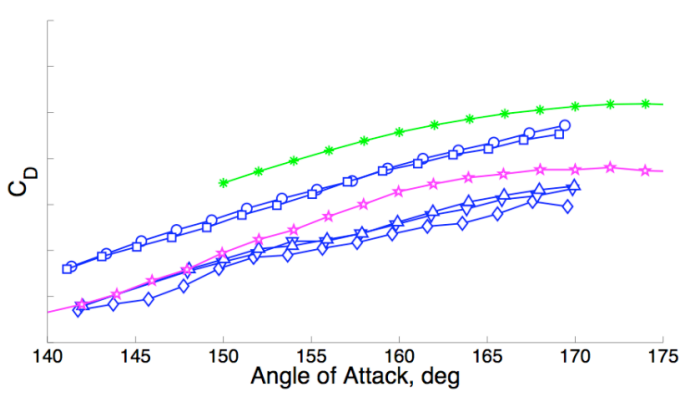

(a) $\mathrm{C}_{\mathrm{D}}$ versus $\alpha$

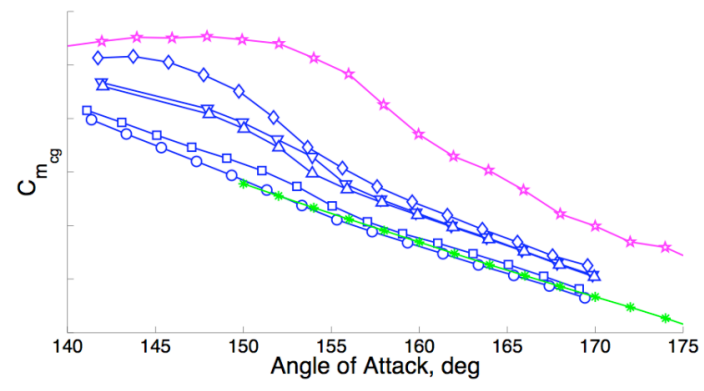

(c) $\mathbf{C}_{\mathrm{m}}$ versus $\alpha$

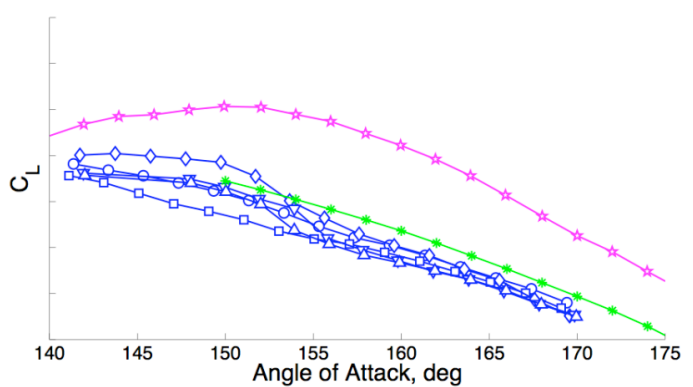

(b) $\mathrm{C}_{\mathrm{L}}$ versus $\alpha$

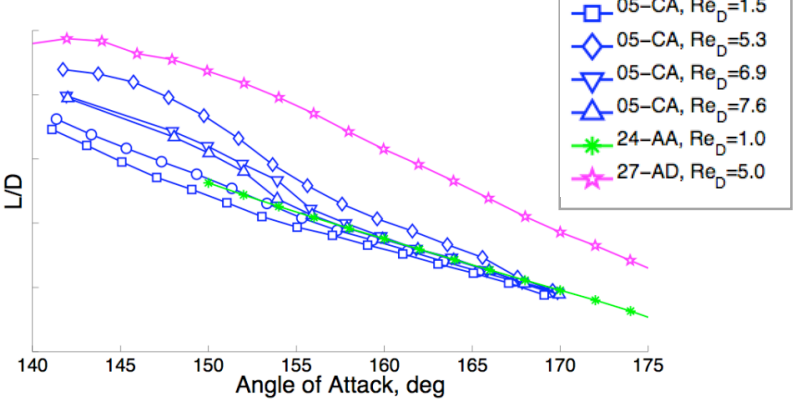

(d) $L / D$ versus $\alpha$

Figure 19. Crew module longitudinal aerodynamic data as a function of angle of attack for $M_{\infty}=0.5$.

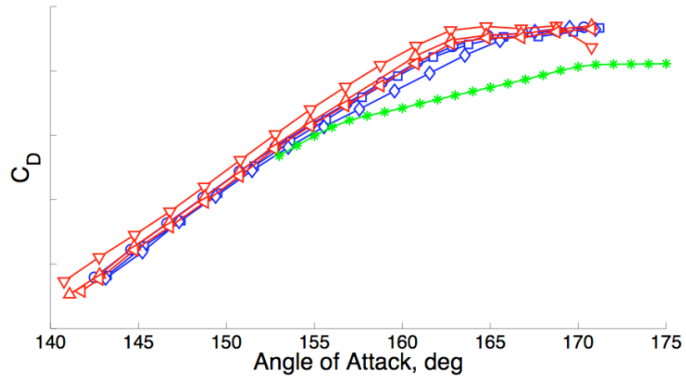

(a) $\mathrm{C}_{\mathrm{D}}$ versus $\alpha$

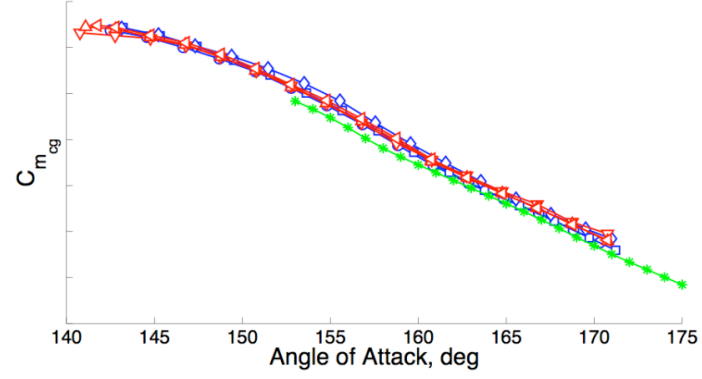

(c) $\mathbf{C}_{\mathrm{m}}$ versus $\alpha$

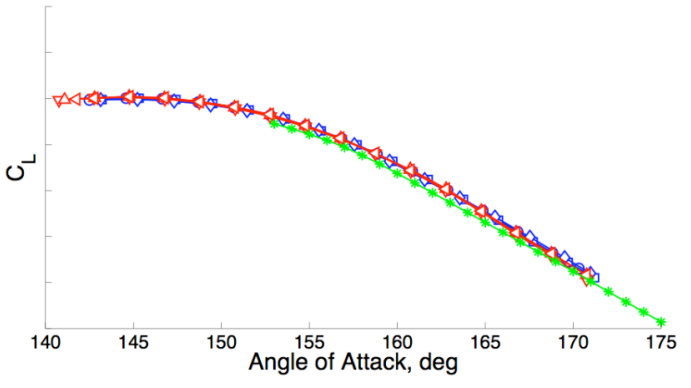

(b) $\mathrm{C}_{\mathrm{L}}$ versus $\alpha$

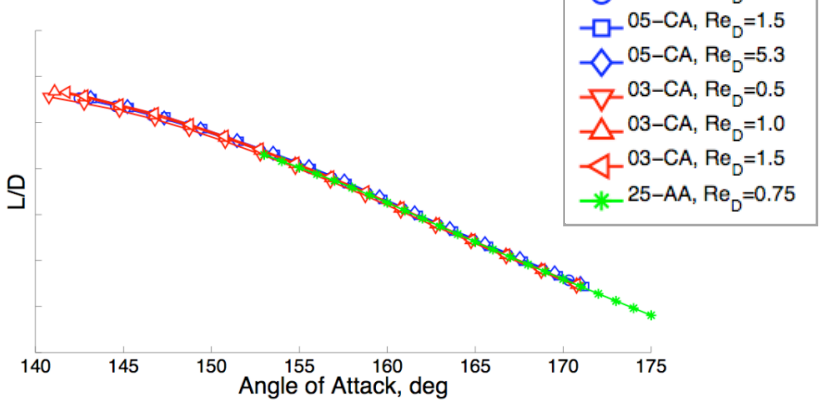

(d) $L / D$ versus $\alpha$

Figure 20. Crew module longitudinal aerodynamic data as a function of angle of attack for $M_{\infty}=1.6$. 
Hypersonic Data: All hypersonic data were generated in a single test with six models used to cover the large angle-of-attack range of $0^{\circ}$ to $180^{\circ}$, as described in a preceding section. Overall the merging of the data from one model to the next was good. The largest discrepancy between models was in the angle of attack range around $60^{\circ}$, primarily seen in the pitching moment data, with lesser effects observed in the lift and lift-to-drag data. This offset was suspected to be due to shear layer impingement on the balance. A shield could only be fabricated to cover the balance for Model $3\left(-75^{\circ}\right.$ sting exit angle) and this offset in the pitch data was reduced but not eliminated. These effects, while not negligible, are small and do not represent gross changes in the vehicle behavior. Offsets between data sets from other models are not significant. As expected, drag is a maximum in the vicinity of $\alpha=180^{\circ}$, with the full projected area of the blunt heatshield facing the freestream flow. Figure 21(c) shows three trim points over the full angle of attack range, with the trim angle near $160^{\circ}$ producing the highest $\mathrm{L} / \mathrm{D}$ with a longitudinally stable configuration. No Reynolds number effects will be shown for hypersonic data in subsequent sections because no significant changes were observed over the small range of $\mathrm{Re}_{\mathrm{D}}$ able to be generated by the Mach 6 facility.

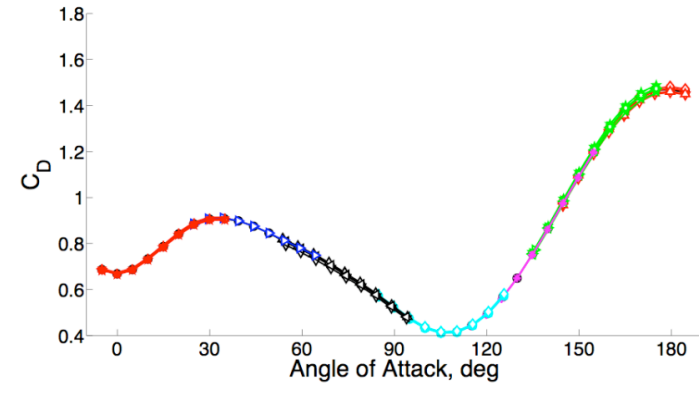

(a) $\mathrm{C}_{\mathrm{D}}$ versus $\alpha$

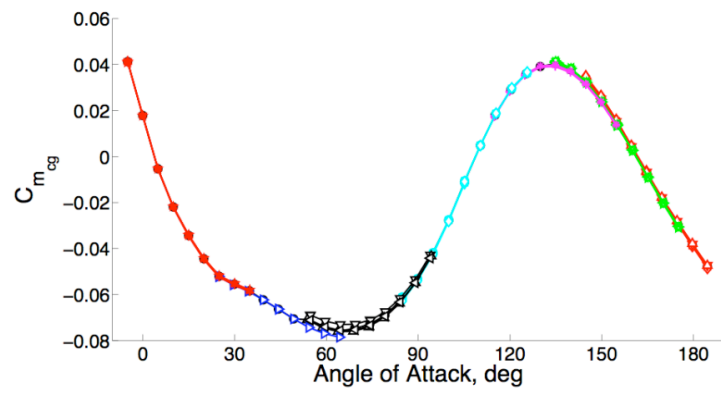

(c) $\mathrm{C}_{\mathrm{m}}$ versus $\alpha$

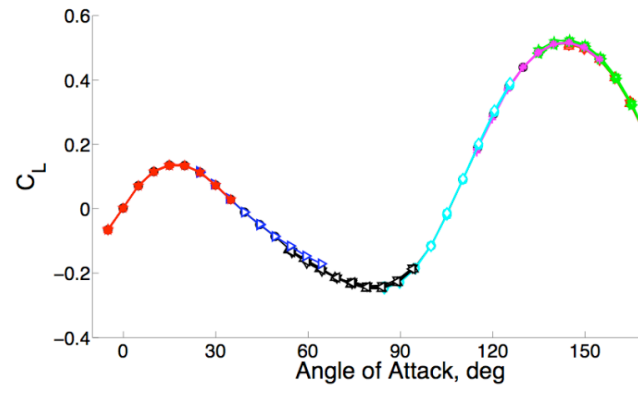

(b) $\mathrm{C}_{\mathrm{L}}$ versus $\alpha$

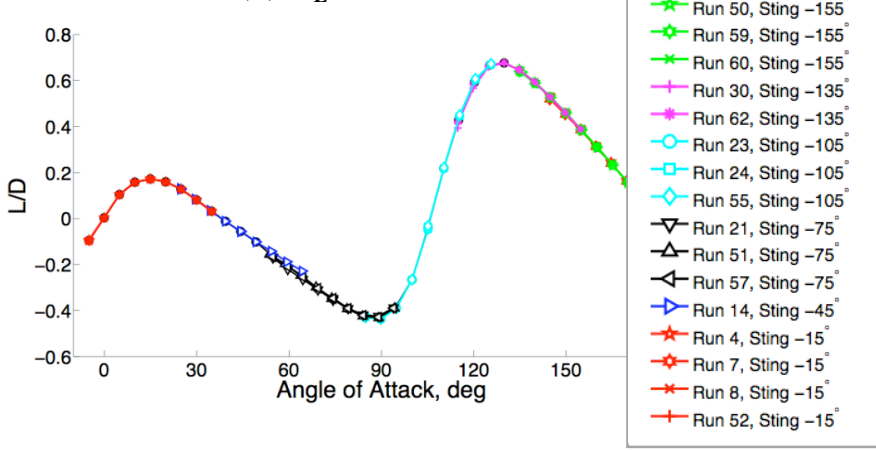

(d) $L / D$ versus $\alpha$

Figure 21. Crew module longitudinal aerodynamic data as a function of angle of attack for $M_{\infty}=6$.

\section{Uncertainty/Repeatability}

The Orion program has made a significant effort to characterize and calculate data uncertainty as part of database development. A detailed explanation of uncertainty methodologies and assumptions for crew module aerodynamic data can be found in Reference 3. Overall uncertainty is calculated using contributing uncertainties components, including OML variations, flow simulation parameter differences, and computational and experimental uncertainties.

Uncertainty calculation for wind tunnel data accuracy, $\sigma_{\mathrm{wt}}$, employs an RSS methodology with terms for run-to-run repeatability, $\sigma_{\mathrm{wt} R \mathrm{RR}}$ and balance accuracy, $\sigma_{\mathrm{wt} \text { bal }}$

$$
\sigma_{w t}=\sqrt{\left(\sigma_{w t R R}\right)^{2}+\left(\sigma_{w t b a l}\right)^{2}}
$$

The balance accuracy term in Equation 1 was developed from balance calibration data for each of the balances used in various test programs, details of which can be found in CAP test program reports. The 
wind tunnel repeatability term was developed as a function of Mach number and angle of attack based on repeat run data from the various wind tunnel tests. As a companion to the data presented in subsequent sections, Table 4 shows average repeatability for longitudinal aerodynamic coefficients each Mach number where test data was acquired and used to build the aerodynamic database.

Table 4. Wind tunnel repeatability for selected longitudinal aerodynamic coefficient data for the Orion crew module.

\begin{tabular}{|c|c|c|c|c|}
\hline Mach & $\boldsymbol{C D}$ & $\boldsymbol{C L}$ & $\boldsymbol{C m}$ & $\boldsymbol{L} / \boldsymbol{D}$ \\
\hline 0.3 & 0.00333 & 0.00536 & 0.00066 & 0.00862 \\
\hline 0.5 & 0.00425 & 0.00754 & 0.00113 & 0.01177 \\
\hline 0.7 & 0.00422 & 0.00685 & 0.00071 & 0.01002 \\
\hline 0.8 & 0.00280 & 0.00220 & 0.00011 & 0.00120 \\
\hline 0.95 & 0.00541 & 0.00284 & 0.00060 & 0.00366 \\
\hline 1.05 & 0.00582 & 0.00241 & 0.00050 & 0.00054 \\
\hline 1.1 & 0.00508 & 0.00205 & 0.00035 & 0.00049 \\
\hline 1.2 & 0.00202 & 0.00188 & 0.00011 & 0.00158 \\
\hline 1.4 & 0.00065 & 0.00097 & 0.00012 & 0.00092 \\
\hline 1.6 & 0.00055 & 0.00029 & 0.00005 & 0.00017 \\
\hline 2.5 & 0.00267 & 0.00035 & 0.00012 & 0.00064 \\
\hline 3 & 0.00023 & 0.00010 & 0.00003 & 0.00013 \\
\hline 4 & 0.00011 & 0.00038 & 0.00010 & 0.00034 \\
\hline 6 & 0.00160 & 0.00090 & 0.00010 & 0.00090 \\
\hline
\end{tabular}

Mach Number Effects

The static aerodynamic database for the symmetric crew module configuration directly used experimental data from three wind tunnel tests, 5-CA ( $\mathrm{M}_{\infty}=0.3$ to 2.5$)$, 3-CA $\left(\mathrm{M}_{\infty}=2.5\right.$ to 4$)$, and 9-CA $\left(\mathrm{M}_{\infty}=6\right)$, as inputs for database creation. Figures 22-25 show the effects of Mach number on stability axis longitudinal aerodynamic coefficients from these three test entries. The data are arbitrarily separated and plotted in 4 groups to facilitate viewing data trends.

Figure 22 shows subsonic and transonic data for Mach numbers $0.3,0.5,0.7$, and 0.9 as a function of angle of attack, from approximately $140^{\circ}$ to $170^{\circ}$ at a Reynolds number of $5.3 \times 10^{6}$. Data show a systematic increase in drag coefficient with increasing Mach number above $\mathrm{M}_{\infty}=0.6$ with nearly constant increments across the angle of attack range. The changes in drag between $M_{\infty}=0.3$ and $M_{\infty}=0.5$ are much smaller and vary with angle of attack. For all data, the highest angles of attack produce the highest drag coefficients and the highest lift coefficients. For angles of attack less than $160^{\circ}$, lift curves become less linear with decreasing Mach number. All data are longitudinally stable for the given moment reference center. Data at $\mathrm{M}_{\infty}=0.7$ and above have similar stability levels over the full alpha range, while lower Mach number data show decreasing stability (to essentially neutral values at the lowest angles of attack) with decreasing $\mathrm{M}_{\infty}$ and $\alpha$. Trim points are observed in $\alpha$ range of $165-170^{\circ}$ for data at $\mathrm{M}_{\infty}=0.7$ and above. Trim angles increase and have to be extrapolated for Mach numbers below 0.7. L/D data show increasing linearity with $\mathrm{M}_{\infty}$ and Mach number independence with increasing angle of attack.

Figure 23 is similar presentation of longitudinal data for transonic and low supersonic Mach numbers, $0.9,0.95,1.05,1.1,1.2,1.4$, and 1.6 at a Reynolds number of $5.3 \times 10^{6}$. Increasing $C_{D}$ with increasing angle of attack trends continue, but no longer with consistent increments with Mach number. The expected drag coefficient increase as the freestream flow goes supersonic is clearly observed and followed by a very small decrease at $M_{\infty}=1.2$ for all but a few angles of attack near $160^{\circ}$. Another drag coefficient increase of comparable magnitude is observed at $\mathrm{M}_{\infty}=1.4$ for all angles of attack with minimal changes occurring as the Mach number increases to 1.6. Lift curve slopes are linear for all but the two highest Mach numbers in the lower half of the angle of attack range, where lift coefficient begins to 


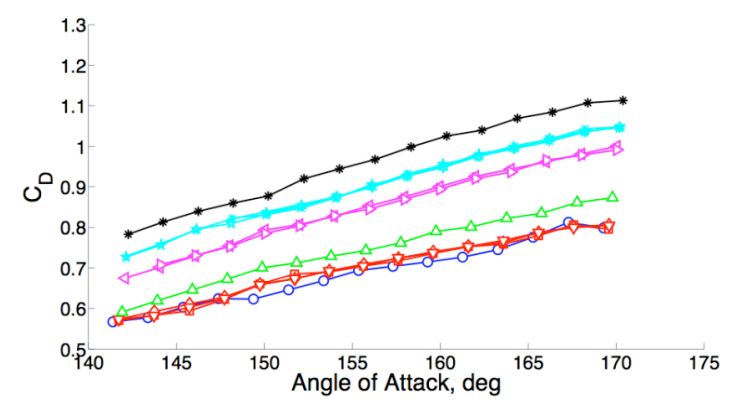

(a) $C_{D}$ versus $\alpha$

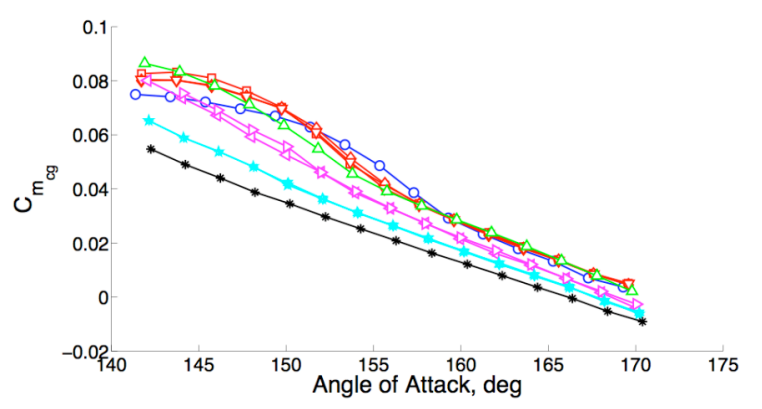

(c) $C_{m}$ versus $\alpha$

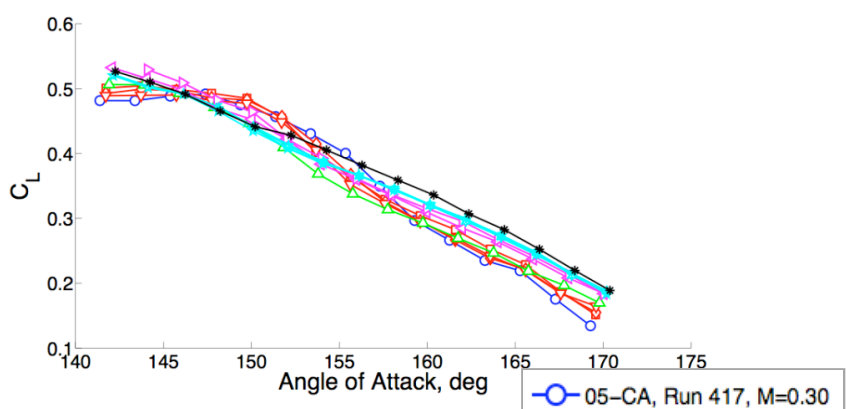

(b) $\mathrm{C}_{\mathrm{L}}$ versus $\alpha$

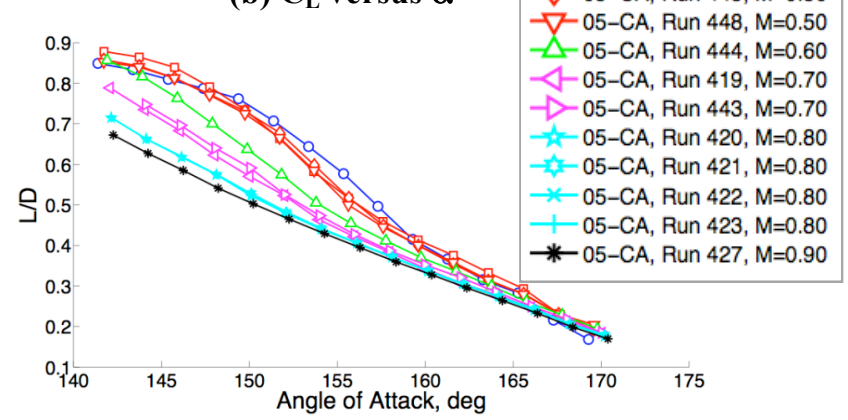

(d) L/D versus $\alpha$

Figure 22. Crew module longitudinal aerodynamic data as a function of angle of attack for $M_{\infty}=\mathbf{0 . 3}$, $0.5,0.7$, and 0.9 at $R_{D}=5.3 \times 10^{6}$ from CAP Test 5-CA.

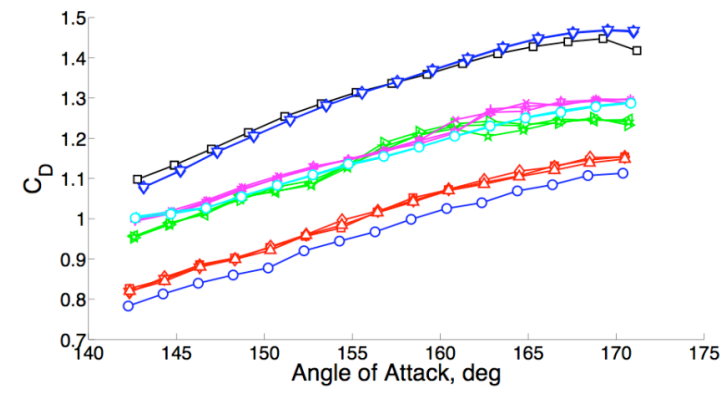

(a) $C_{D}$ versus $\alpha$

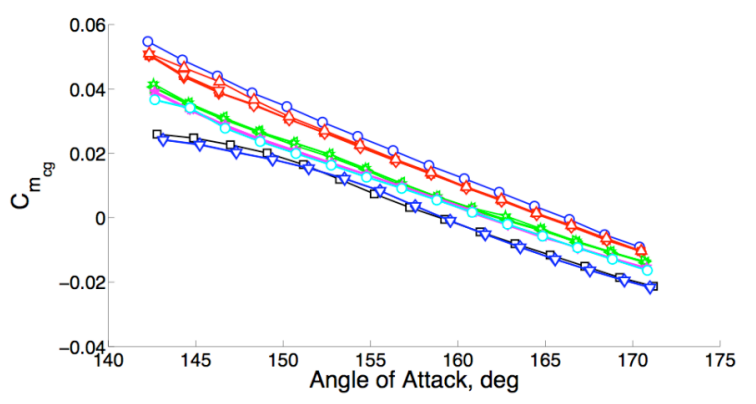

(c) $\mathbf{C}_{\mathrm{m}}$ versus $\alpha$

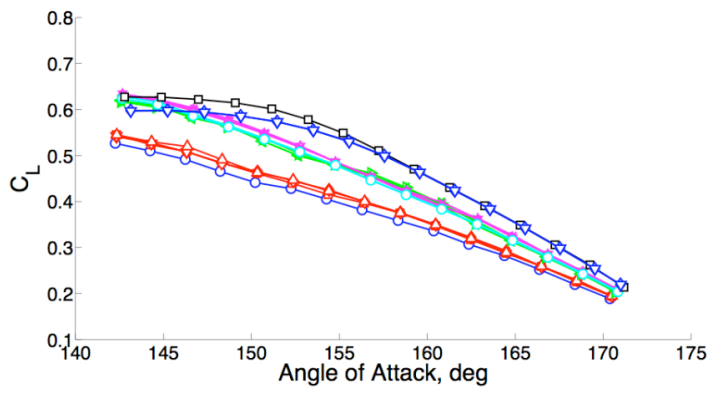

(b) $\mathrm{C}_{\mathrm{L}}$ versus $\alpha$

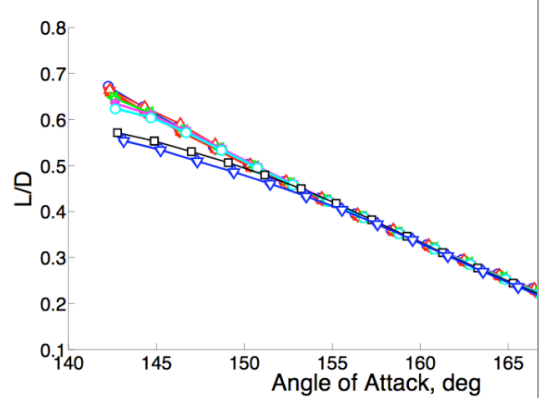

-O- 05-CA, Run 427, M=0.90 - $-05-C A$, Run 424, $M=0.95$ 05-CA, Run 425, $M=0.95$ - 05-CA, Run 426, $M=0.95$ $\triangle$ 05-CA, Run 441, $M=0.95$ $-05-C A$, Run 433, $M=1.05$ $\rightarrow-05-C A$, Run $434, M=1.05$ 는 $05-C A$, Run $440, M=1.05$ - 05-CA, Run 431, $M=1.10$ $\rightarrow$ 05-CA, Run 432, $M=1.10$ + 05-CA, Run 437, $M=1.10$ * 05-CA, Run 430, $M=1.20$ -05-CA, Run 436, $M=1.20$ $-\square-05-C A$, Run 429, $M=1.40$ 05-CA, Run 124, $M=1.60$ $\checkmark$-05-CA, Run 133, $M=1.60$

(d) $L / D$ versus $\alpha$

Figure 23. Crew module longitudinal aerodynamic data as a function of angle of attack for $M_{\infty}=0.9,0.95$, $1.05,1.1,1.2,1.4$, and 1.6 at $\operatorname{Re}_{D}=5.3 \times 10^{6}$ from CAP Test 5-CA. 


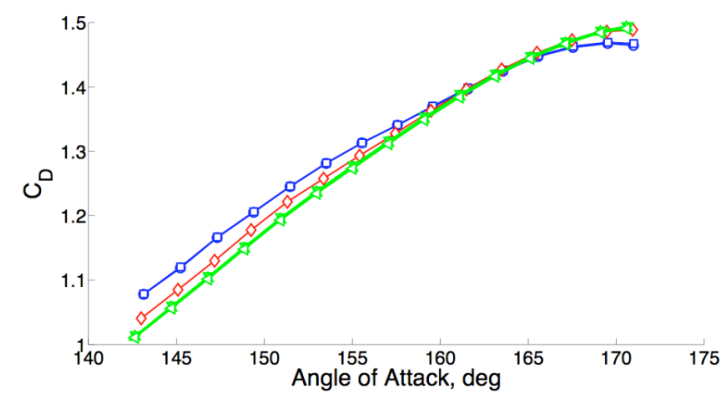

(a) $\mathrm{C}_{\mathrm{D}}$ versus $\alpha$

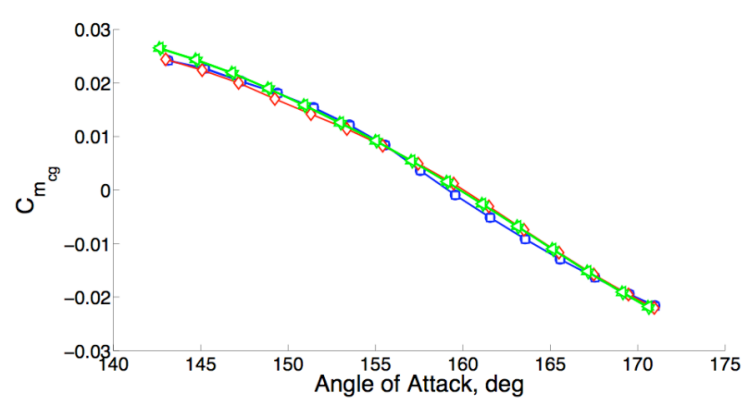

(c) $\mathbf{C}_{\mathrm{m}}$ versus $\alpha$

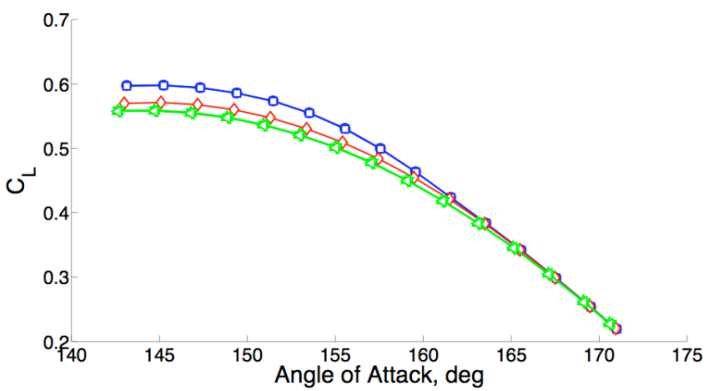

(b) $\mathrm{C}_{\mathrm{L}}$ versus $\alpha$

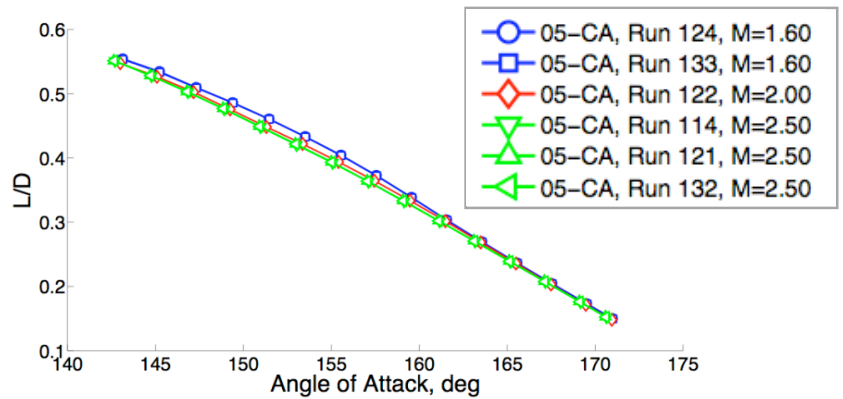

(d) $L / D$ versus $\alpha$

Figure 24. Crew module longitudinal aerodynamic data as a function of angle of attack for $M_{\infty}=1.6$, 2, and 2.5 at $\operatorname{Re}_{\mathrm{D}}=5.3 \times 10^{6}$ from CAP Test 5-CA.

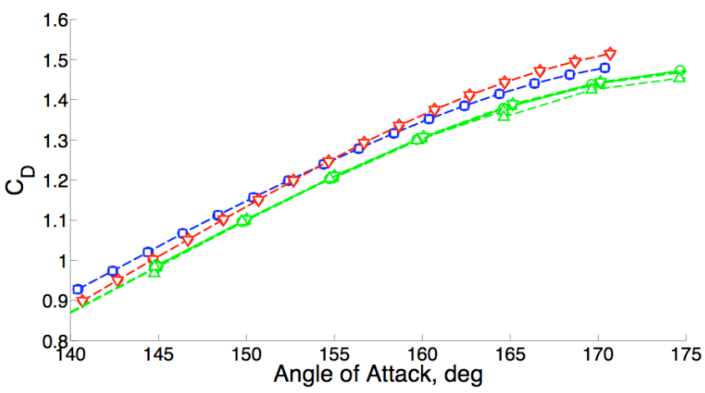

(a) $C_{D}$ versus $\alpha$

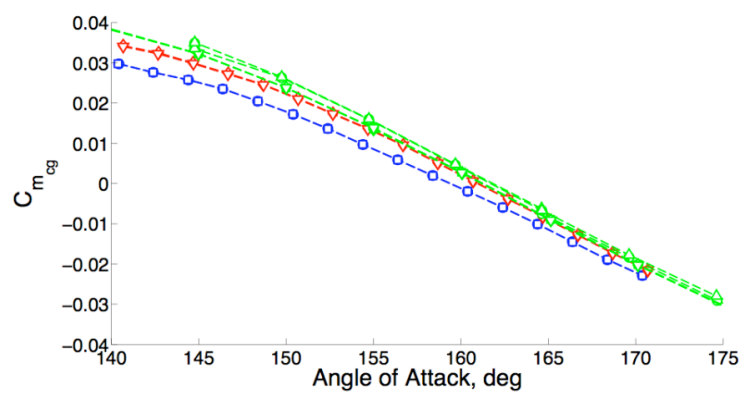

(c) $\mathrm{C}_{\mathrm{m}}$ versus $\alpha$

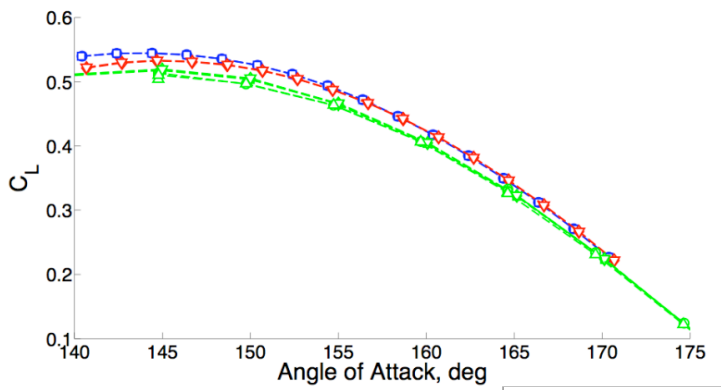

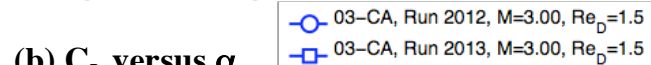

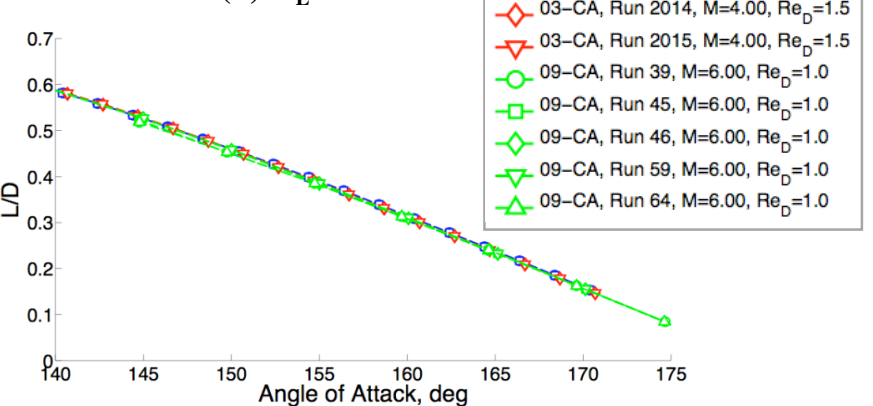

(d) $L / D$ versus $\alpha$

Figure 25. Crew module longitudinal aerodynamic data as a function of angle of attack for $M_{\infty}=3,4$, and 6 at $\operatorname{Re}_{\mathrm{D}}=1 \times 10^{6}-1.5 \times 10^{6}$ from CAP Tests 3-CA and 9-CA. 
decrease with Mach number at $\mathrm{M}_{\infty}=1.6$. Linear pitching moment stability trends continue with a move towards neutral stability above $\mathrm{M}_{\infty}=1.4$ for the lowest angles of attack. Lift-to-drag ratio is essentially independent of Mach number through the transonic range with the exception of the lowest angles of attack above $\mathrm{M}_{\infty}=1.4$ where lower values are observed corresponding to the aforementioned changes in lift and drag coefficients for these conditions.

Figures 24 and 25 show the effect of Mach number variation for supersonic and hypersonic test conditions. Figure 24 shows supersonic data for $\operatorname{Re}_{D}=5.3 \times 10^{6}$, and Figure 25 shows supersonic and hypersonic data for $\operatorname{Re}_{\mathrm{D}}=1 \times 10^{6}-1.5 \times 10^{6}$. Data are presented with the same or very close Reynolds number values in order to show only the effects of Mach number. (Effects of Reynolds number will be discussed in the next section.) All longitudinal components begin to collapse and exhibit much less variation with Mach number than preceding subsonic and transonic data. Drag and lift coefficients continue to decrease slightly with Mach number with the exception of $C_{D}$ at $M_{\infty}=4$ for $\alpha>155^{\circ}$. Stability increases slightly with increasing Mach number, with trim angles changing only a few degrees across the entire Mach range. These data show $\mathrm{L} / \mathrm{D}$ to be essentially a function of angle of attack above $\mathrm{M}_{\infty}=2$.

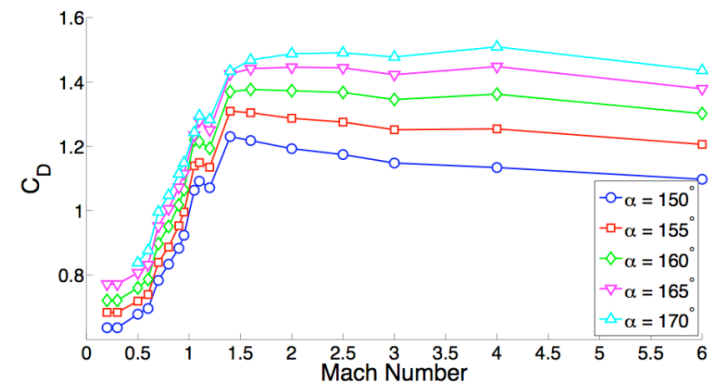

(a) $C_{D}$ versus $M$

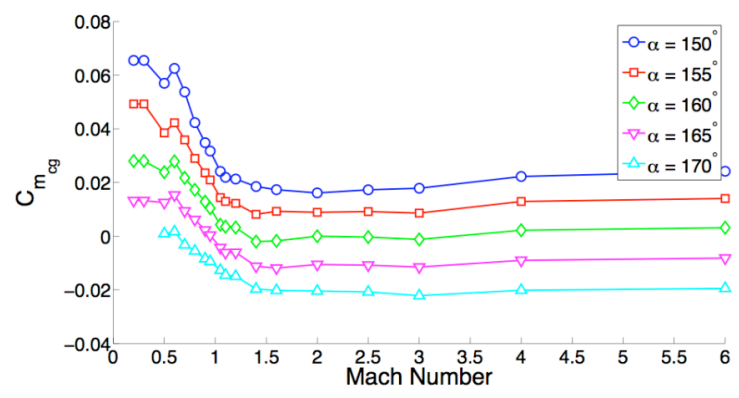

(c) $\mathrm{C}_{\mathrm{m}}$ versus $\mathrm{M}$

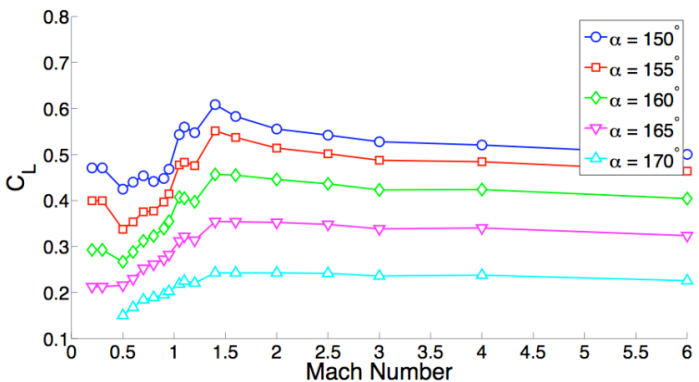

(b) $\mathrm{C}_{\mathrm{L}}$ versus $\mathrm{M}$

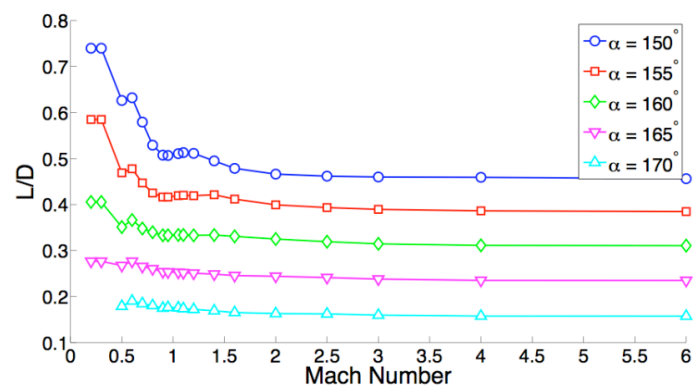

(d) $L / D$ versus $M$

Figure 26. Crew module longitudinal aerodynamic as a function of Mach number for $\alpha=150-170^{\circ}$, $\operatorname{Re}_{\mathrm{D}}=1 \times 10^{6}-5.3 \times 10^{6}$ from CAP Tests 3-CA, 5-CA, and 9-CA.

Figure 26 shows the same longitudinal stability axis data from Figures 22-25 now plotted as function of Mach number, with each curve representing an individual angle of attack. Note that these data points are interpolated at specific angles of attack. Data shown correspond to the highest Reynolds number available for each data point, as presented in the preceding figures (i.e. they are not constant for each curve). Very little Reynolds number variation was possible at high supersonic and hypersonic test conditions and thus Reynolds number variations had no significant effect on observed trends. The plot of drag coefficient versus Mach number clearly highlights the highly non-linear increase in $C_{D}$ through the subsonic and transonic regimes, with the small decrease at $\mathrm{M}_{\infty}=1.2$ clearly evident at all angles of attack. The small increase in drag coefficient at Mach 4 is now easily seen to increase with increasing angle of attack. Subsonic and transonic lift coefficient data show increasing non-linearity with decreasing angle of attack. $\mathrm{C}_{\mathrm{L}}$ reaches a maximum at $\mathrm{M}_{\infty}=1.4$ for the range of angle of attack shown. Pitching moment coefficient data trend similarly for all angles of attack with fairly constant increments between angles of attack. As seen in 


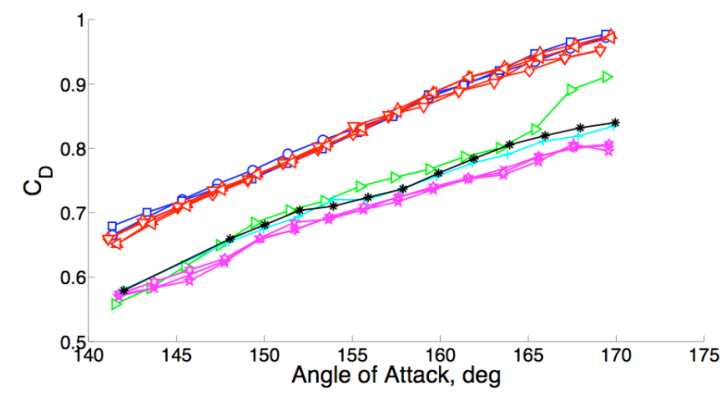

(a) $C_{D}$ versus $\alpha$

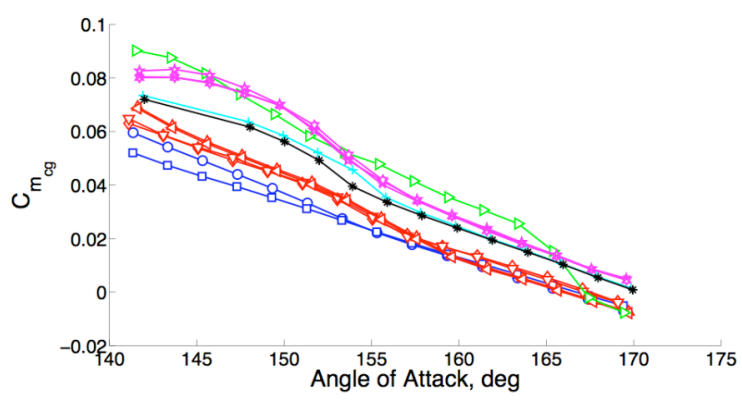

(c) $\mathbf{C}_{\mathrm{m}}$ versus $\alpha$

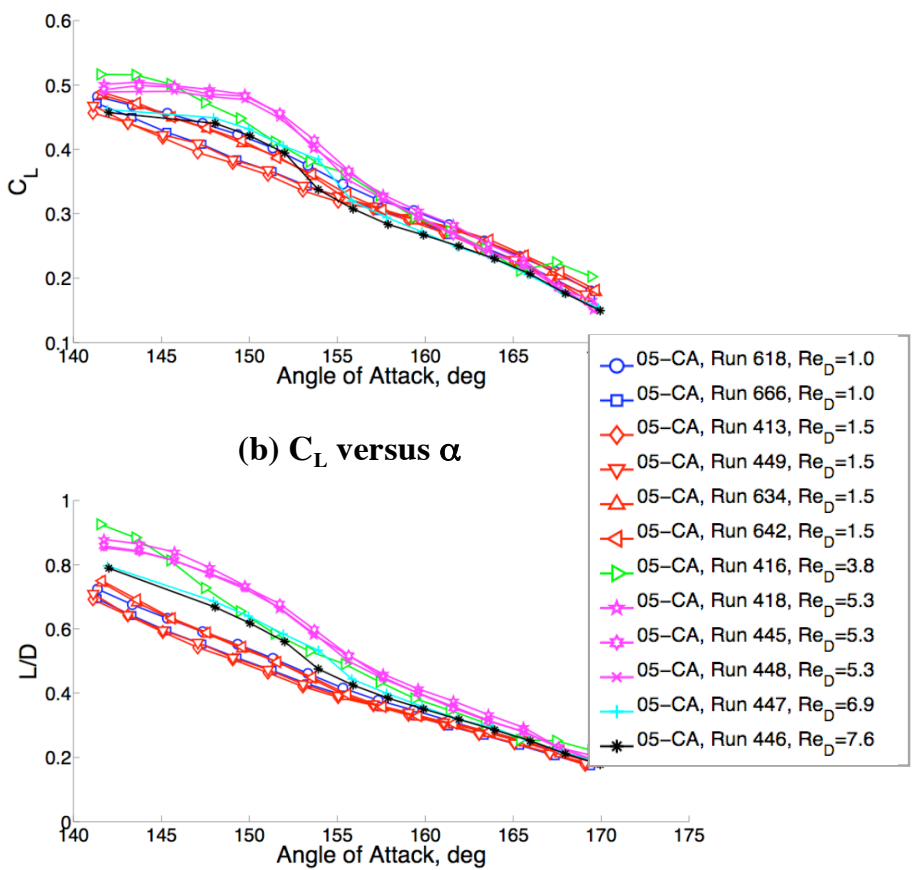

(d) $L / D$ versus $\alpha$

Figure 27. Crew module longitudinal aerodynamic data as a function of angle of attack for $\operatorname{Re}_{\mathrm{D}}=1 \times 10^{6}-7.5 \times 10^{6}$ at $M_{\infty}=0.5$ from CAP Test 5-CA.

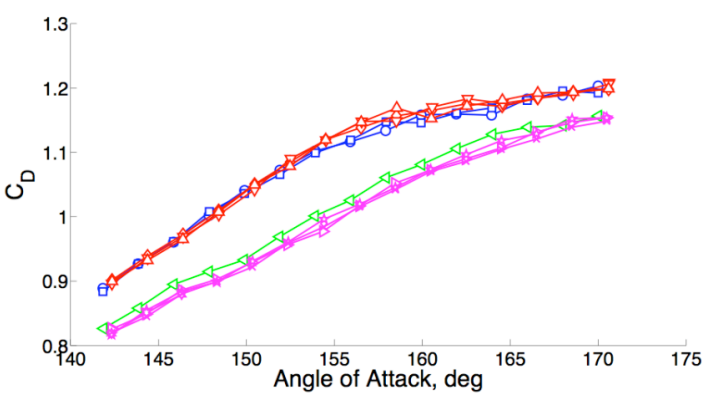

(a) $\mathrm{C}_{\mathrm{D}}$ versus $\alpha$

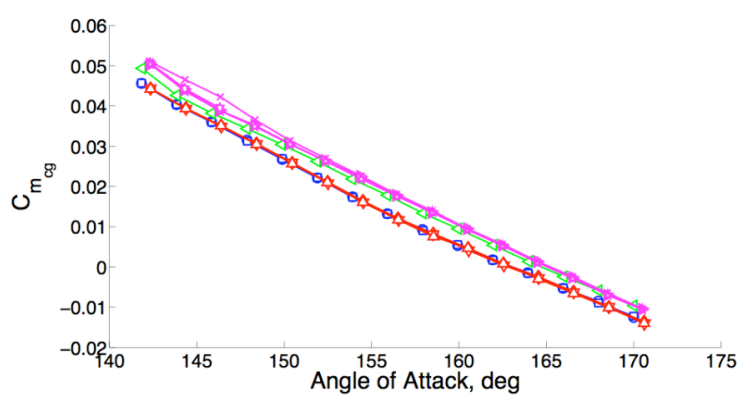

(c) $\mathbf{C}_{\mathrm{m}}$ versus $\alpha$

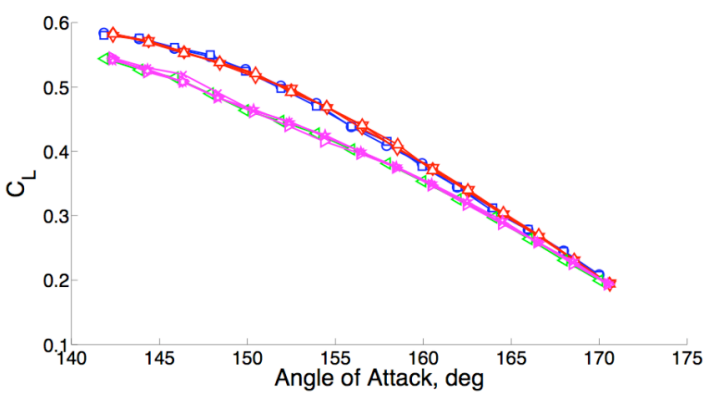

(b) $\mathrm{C}_{\mathrm{L}}$ versus $\alpha$

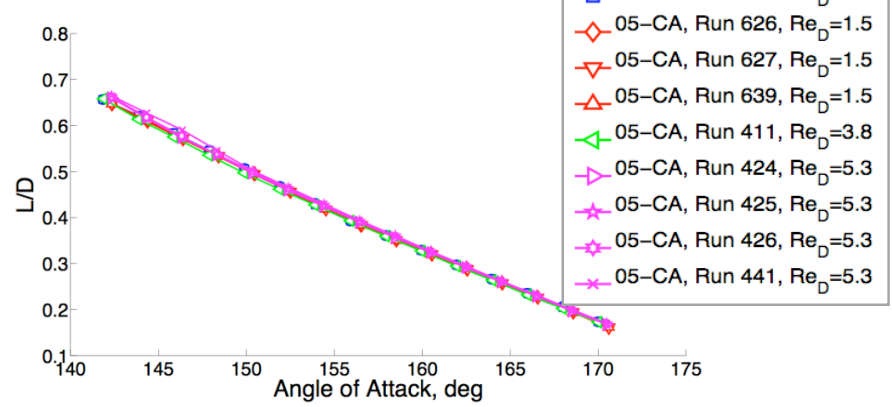

(d) $L / D$ versus $\alpha$

Figure 28. Crew module longitudinal aerodynamic data as a function of angle of attack for $\operatorname{Re}_{D}=1 \times 10^{6}-5.3 \times 10^{6}$ at $M_{\infty}=0.95$ from CAP Test 5-CA. 


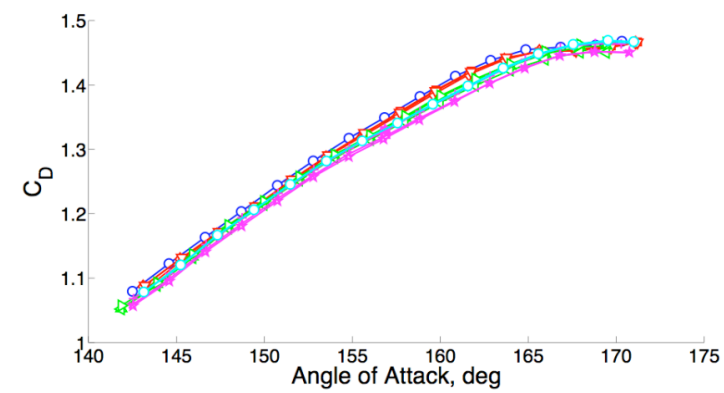

(a) $\mathrm{C}_{\mathrm{D}}$ versus $\alpha$

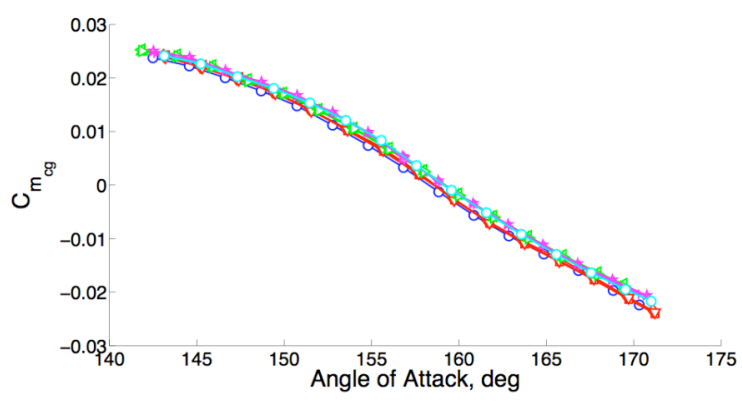

(c) $\mathbf{C}_{\mathrm{m}}$ versus $\alpha$

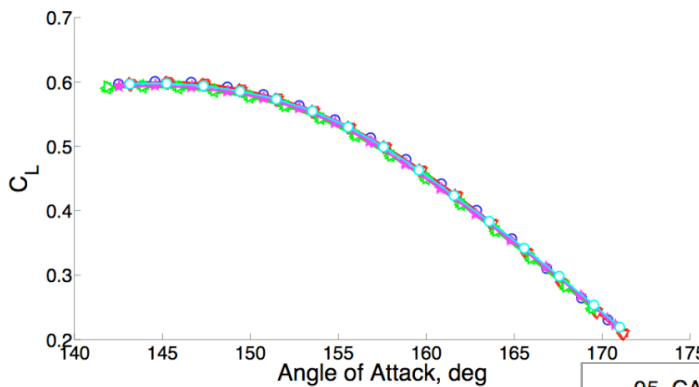

-0 05-CA, Run 331, $\mathrm{Re}_{\mathrm{D}}=1.0$

$-\square-05-C A$, Run 322, $R_{D}=1.5$

(b) $\mathrm{C}_{\mathrm{L}}$ versus $\alpha$

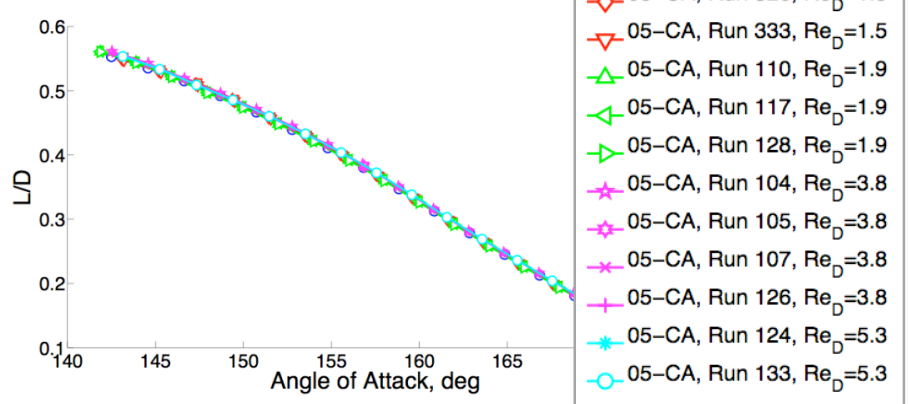

(d) $L / D$ versus $\alpha$

Figure 29. Crew module longitudinal aerodynamic data as a function of angle of attack for $\operatorname{Re}_{\mathrm{D}}=1 \times 10^{6}-7.5 \times 10^{6}$ at $M_{\infty}=1.6$ from CAP Test 5-CA.

Figures 24 and 25, the trim angle changes very little between Mach 2 and 6. Magnitude and variability of lift-to-drag ratio increase with decreasing $\alpha$ for all Mach numbers. $\mathrm{L} / \mathrm{D}$ values show Mach independence for $\mathrm{M}_{\infty}>2$.

\section{Reynolds Number Effects}

Figures 27 - 29 show the effects of Reynolds number on stability axis longitudinal aerodynamic coefficients. The data are presented for three Mach numbers, 0.5, 0.95, and 1.6 to show effects typical of subsonic, transonic, and, supersonic flow conditions. For all longitudinal data shown, Reynolds number effects are the largest at $\mathrm{M}_{\infty}=0.5$. Drag coefficient shows pronounced decrease between $\operatorname{Re}_{\mathrm{D}}=1.5 \times 10^{6}$ and $3.8 \times 10^{6}$ for all but the two highest angles of attack. The drop in $C_{D}$ is accompanied by an increase in the trim angle and an increase in $C_{L}$ magnitude and non-linearity at the lower angles of attack. The trend of decreasing $C_{D}$ with Reynolds number continues through $\mathrm{Re}_{\mathrm{D}}=5.3 \times 10^{6}$ for all angles of attack, then reverses slightly as $\mathrm{Re}_{\mathrm{D}}$ rises to $7.6 \times 10^{6}$. Attempts were made to measure boundary layer transition via PSP by observing the model surface temperature variation during tunnel temperature ramps, but they were unsuccessful due to the inability of the facility to generate large temperature ramps and the insensitivity of the equipment to small temperature changes. ${ }^{8}$ However regions of transition from laminar to turbulent flow remain a possible scenario with increasing Reynolds number. Both static pressure tap and PSP data quantitatively show that Reynolds number, as well as Mach number (as observed in Figure 13 for transonic conditions), significantly affect the size of the suction region on the windward heat shield shoulder at the lower angles of attack. The decrease in extent of this lower pressure region with increasing $\mathrm{Re}_{\mathrm{D}}$ contributes to a decrease in $C_{L}$ and $C_{D}$ and an increase in $C_{m}$ at these lower angles of attack. The complex flow in the entire base region is highly affected by Reynolds number and unfortunately very difficult to model computationally. L/D values change by as much as $30 \%$ over the range of Reynolds numbers tested. Similar trends in all coefficients are observed at $\mathrm{M}_{\infty}=0.95$ (Figure 28) with data available only up to $\operatorname{Re}_{\mathrm{D}}=5.3 \times 10^{6}$. The supersonic data for $\mathrm{M}_{\infty}=1.6$ (Figure 29) show much less sensitivity to Reynolds number. 


\section{Summary}

A strategic wind-tunnel test program has been executed at numerous facilities throughout the country to support several phases of aerodynamic database development of the Orion crew module, recently selected as the reference vehicle design for the new Multi-Purpose Crew Vehicle. Static force and moment tests have been done in the subsonic, transonic, supersonic, and hypersonic speed regimes focused on reentry aerodynamics of the crew module configuration. CM data were generated in eight separate CAP wind tunnel test programs, three of which were used as direct inputs to create the aerodynamic database. Companion static and dynamic surface pressure data were also generated, in addition to use of qualitative surface visualization techniques to aid in data interpretation of experimental data and validation of computational results. Variation of angle of attack, Mach number, and Reynolds number were all shown to have significant effects on longitudinal aerodynamics of the CM configuration. The largest variations and non-linearities were observed at subsonic test conditions. Reynolds number deficiency is shown to be a key limitation in the available subsonic data sets and a source of significant uncertainty in this speed regime.

\section{References}

${ }^{1}$ http://www.nasa.gov/mission pages/constellation/orion/orion announcement.html, last accessed, 6 June 2011.

${ }^{2}$ http://www.nasa.gov/pdf/163092main_constellation_program_overview.pdf, last accessed, 6 June 2011.

${ }^{3}$ Ross, J.C., Brauckmann, G.J., "Aerodynamic and Aeroacoustic Wind Tunnel Testing of the Orion Spacecraft," 29th Applied Aerodynamics Conference, AIAA, Hawaii (submitted for publication).

${ }^{4}$ Bibb, K.L., Robinson, P., Brauckmann, G.J., "Development of the Orion Crew Module Static Aerodynamic Database, Part II: Subsonic” 29th Applied Aerodynamics Conference, AIAA, Hawaii (submitted for publication).

${ }^{5}$ Stremel, P.M., et al., "Computational Aerodynamic Simulations of the Orion Command Module" 29th Applied Aerodynamics Conference, AIAA, Hawaii (submitted for publication).

${ }^{6}$ Wilson, T.M, "61-AA LAS Jettison Motor and Proximity Wind Tunnel Test for PA-1 and ALAS 11 Rev 3c at the Langley 14'x22' Facility," CEV Aerosciences Program, Rept. EG-CEV-09-5, NASA Johnson Space Center, March 2009.

${ }^{7}$ Owens, D.B., Tomek, D., and Aubuchon, V.V., "18-CD Subsonic-Transonic Crew Module Dynamic Stability Test in the NASA LaRC Transonic Dynamics Tunnel," CEV Aerosciences Program, NASA Langley Research Center, Rept. EG-CEV-07-99, February 2009.

${ }^{8}$ Owens, D.B., Tomek, D., and Aubuchon, V.V., "27-AD Subsonic-Transonic Launch Abort Vehicle Dynamic Stability Test in the NASA LaRC Transonic Dynamics Tunnel," CEV Aerosciences Program, NASA Langley Research Center, Rept. EG-CEV-08-79, December 2008.

${ }^{9}$ Bell, J.H., "Test 5-CA Final Report," CEV Aerosciences Program, Rept. EG-CEV-2006-19, NASA Ames Research Center, March 2006.

${ }^{10}$ Rhode, M.N., "Test 24-AA/25-AA Final Report," CEV Aerosciences Program, Rept. EG-CEV-2010-89, NASA Langley Research Center, July 2011.

\footnotetext{
${ }^{11}$ Murphy, K.J., "Test 3-CA Final Report," CEV Aerosciences Program, Rept. EG-CEV-2006-137, NASA
} Langley Research Center, February 2006. 
${ }^{12}$ Murphy, K.J., et al., “Testing of the Crew Exploration Vehicle in NASA Langley’s Unitary Plan Wind Tunnel," AIAA Paper 2007-1005, 45 ${ }^{\text {th }}$ Aerospace Sciences Meeting and Exhibit, Reno, NV, January 2007.

${ }^{13}$ Brauckmann, G.J.,, "Final Report for CEV Test 9-CA: Mach $60^{\circ}$ to $180^{\circ}$ Hypersonic Aerodynamics," CEV Aerosciences Program, Rept. EG-CEV-2006-152, NASA Langley Research Center, November 2006. 